\title{
Casein kinase 2-dependent serine phosphorylation of MuSK regulates acetylcholine receptor aggregation at the neuromuscular junction
}

\author{
Tatiana Cheusova, ${ }_{1}^{1}$ Muhammad Amir Khan, ${ }^{1}$ Steffen Wolfgang Schubert, ${ }^{1}$ Anne-Claude Gavin, ${ }^{2}$ \\ Thierry Buchou, ${ }^{3}$ Germaine Jacob, ${ }^{4}$ Heinrich Sticht, ${ }^{1}$ Jorge Allende, ${ }^{4}$ Brigitte Boldyreff, ${ }^{5}$ \\ Hans Rudolf Brenner, ${ }^{2}$ and Said Hashemolhosseini ${ }^{1,6}$ \\ ${ }^{1}$ Institut für Biochemie, Universität Erlangen-Nürnberg, D-91054 Erlangen, Germany; ${ }^{2}$ Department of Physiology, \\ Biozentrum/Pharmazentrum, University of Basel, CH-4056 Basel, Switzerland; ${ }^{3}$ DRDC/TS INSERM EMI 0104, 38054 \\ Grenoble cedex 9, France; ${ }^{4}$ Laboratorio de Biología Molecular de la Transducción de Señales Celulares, Programa de Biología \\ Celular y Molecular, Instituto de Ciencias Biomédicas, Facultad de Medicina, Universidad de Chile, Chile; ${ }^{5}$ KinaseDetect, \\ Research and Development, DK-5230 Odense M, Denmark
}

The release of Agrin by motoneurons activates the muscle-specific receptor tyrosine kinase (MuSK) as the main organizer of subsynaptic specializations at the neuromuscular junction. MuSK downstream signaling is largely undefined. Here we show that protein kinase CK2 interacts and colocalizes with MuSK at post-synaptic specializations. We observed CK2-mediated phosphorylation of serine residues within the kinase insert (KI) of MuSK. Inhibition or knockdown of CK2, or exchange of phosphorylatable serines by alanines within the KI of MuSK, impaired acetylcholine receptor (AChR) clustering, whereas their substitution by residues that imitate constitutive phosphorylation led to aggregation of AChRs even in the presence of CK2 inhibitors. Impairment of AChR cluster formation after replacement of MuSK KI with KIs of other receptor tyrosine kinases correlates with potential CK2-dependent serine phosphorylation within KIs. MuSK activity was unchanged but AChR stability decreased in the presence of CK2 inhibitors. Muscle-specific CK2 $\beta$ knockout mice develop a myasthenic phenotype due to impaired muscle endplate structure and function. This is the first description of a regulatory cross-talk between MuSK and CK2 and of a role for the KI of the receptor tyrosine kinase MuSK for the development of subsynaptic specializations.

[Keywords: MuSK; CK2; casein kinase; synapse; skeletal muscle; neuromuscular junction]

Supplemental material is available at http://www.genesdev.org.

Received December 7, 2005; revised version accepted April 25, 2006.

Synapses ensure proper neurochemical transmission of information between billions of nerve cells in the human central and peripheral nervous systems. Synaptogenesis requires reciprocal focal signaling between cells that results in the differentiation of pre- and post-synaptic specializations arranged precisely opposite of one another. These specializations contain at the presynaptic site a high number of organelles and molecules involved in synthesis, packaging, and release of neurotransmitter. In the post-synaptic cell membrane, a high density of neurotransmitter receptors ensures a rapid and reliable response to the transmitter (Sanes and Lichtman 1999). The neuromuscular junction (NMJ) is a specialized synapse that is particularly suited for investigating the de-

${ }^{6}$ Corresponding author.

E-MAIL sh@biochem.uni-erlangen.de; FAX 49-9131-85-22484.

Article is online at http://www.genesdev.org/cgi/doi/10.1101/gad.375206. velopment of synaptic specializations because of its simplicity, size, and experimental accessibility (Sanes and Lichtman 1999). Molecular defects at the NMJ furthermore cause diseases such as congenital myasthenic syndromes or myasthenia gravis (McConville and Vincent 2002).

At the NMJ, subsynaptic specializations, including the high density of acetylcholine receptors (AChR), are mainly organized by the muscle-specific receptor tyrosine kinase MuSK upon activation by Agrin, a proteoglycan secreted by the motor nerve. Ablation of Agrin and $M u S K$ genes has demonstrated the indispensability of Agrin and MuSK for NMJ formation (Sanes and Lichtman 1999). Intrinsic MuSK kinase activity is initiated upon phosphorylation of MuSK on several tyrosine residues in its kinase activation loop and the juxtamembrane region (Zhou et al. 1999; Herbst and Burden 2000; Watty et al. 2000). Phosphorylated tyrosine residues 
serve as docking sites for proteins involved in downstream signaling. It is thought that MuSK-mediated tyrosine phosphorylation of AChRs facilitates their interaction with molecules of the cytoskeleton such as Factin (Dai et al. 2000), leading to focal accumulation of AChRs through lateral diffusion. In addition to several tyrosine residues, a phosphorylated serine residue was reported on the MuSK kinase insert (KI). The KI is an epitope of disordered and exposed conformation present in many receptor tyrosine kinases. It divides the tyrosine kinase domain into two subdomains (Ullrich and Schlessinger 1990; Heldin 1995; Till et al. 2002), However, its function in most of these kinases, including MuSK, is unknown.

Downstream signaling of MuSK phosphorylation is poorly understood. Activated MuSK associates with Src class kinases and Abl, both of which are required for the stabilization of AChR clusters in cultured muscle cells (Mohamed et al. 2001; Finn et al. 2003; Sadasivam et al. 2005). Furthermore, members of the Rho family of small GTPases are involved in different steps of AChR aggregation (Weston et al. 2000, 2003), as well as in Agrin-induced $A C h R$ and MuSK gene transcription (Lacazette et al. 2003). Therefore, activated MuSK appears to initiate downstream signaling cascades of tyrosine phosphorylation through Abl and Src class kinases on the one hand, and through the Rho family of kinases on the other, inducing both transcription of $A C h R$ genes and aggregation of the AChRs. However, their physiological significance has not been demonstrated in vivo.

Here, we aimed to elucidate MuSK downstream signaling events by identification of proteins associated with the intracellular domain of MuSK. By performing a yeast two-hybrid screen, we identified the protein kinase CK2 $\beta$ subunit (the holoenzyme was formerly called casein kinase 2) able to interact with the intracellular part of MuSK. CK2 is a highly conserved, ubiquitously expressed serine/threonine kinase present in all eukaryotes (Meggio and Pinna 2003; Olsten and Litchfield 2004). It is involved in many biological processes, such as proliferation, apoptosis, differentiation, and tumorigenesis. The CK2 holoenzyme consists of a tetramer of two catalytic $\left(\alpha / \alpha^{\prime}\right)$ and two regulatory $(\beta)$ subunits. Ablation studies have demonstrated the inability of CK2 $\alpha$ to compensate for the loss of CK2 $\alpha^{\prime}$ during mouse spermatogenesis (Xu et al. 1999; Escalier et al. 2003), suggesting functional specialization. In mice, disruption of the gene encoding the CK2 $\beta$ subunit is lethal at a very early embryonic stage (Buchou et al. 2003). The precise mode of regulation of CK2 activity is poorly defined; i.e., whether CK2 is constitutively active or modulated in response to stimuli (Olsten and Litchfield 2004). Recently, the involvement of CK2 in the Wnt/ $\beta$-catenin signaling pathway has been reported (Song et al. 2000, 2003). The planar-cell polarity part of the Wnt/ $\beta$-catenin pathway is also implicated in post-synaptic cytoskeletal reorganization since members of this pathway, namely $\beta$-catenin, Dishevelled, and the tumor suppressor protein adenomatous polyposis coli, directly associate with players of the post-synaptic membrane (Luo et al. 2002, 2003; Wang et al. 2003; Zou 2004).

We now find that CK2 $\beta$ strongly interacts with the phosphorylated intracellular domain of MuSK at the NMJ. This interaction requires the entire intracellular MuSK domain except the C-terminal PDZ-binding motif, as well as the positive regulatory domain of CK2 $\beta$. Further, we demonstrate phosphorylation of serine residues within the KI of MuSK by CK2. Finally, we corroborated our in vitro data by generation and characterization of myotube-specific $C K 2 \beta$ knockout mice.

Our data thus identify CK2-mediated serine phosphorylation of MuSK as a critical step in downstream signaling at the NMJ, and they suggest for the first time a functional role for the KI of MuSK.

\section{Results}

Interaction of CK2 subunits with the intracellular domain of MuSK

We created a yeast two-hybrid bait representing the native intracellular domain of active MuSK. To this end, we fused two complete intracellular MuSK domains by a flexible linker (Fig. 1A; MuSK2xwt). To resolve whether binding of potential MuSK interactors depended on the phosphorylation state of MuSK, we generated a similar construct with an inactive kinase domain (Fig. 1A; MuSK2xkd). Both bait constructs are properly expressed in yeasts and in Cos7 cells (Fig. 1B). Autophosphorylation was seen in MuSK2xwt, but not in MuSK2xkd (Fig. 1B). We screened $\sim 6 \times 10^{6}$ independent yeast colonies with the yeast two-hybrid assay using MuSK2xwt as a bait. One of the candidates we independently identified many times was the $\beta$ subunit of CK2. We confirmed this interaction by coimmunoprecipitations in transiently transfected HEK293 cells (Fig. 1C). It should be noted that HEK293 cells contain additionally endogenous CK2. The CK2 $\beta$ subunit preferentially interacted with the tyrosine-phosphorylated form of the intracellular domain of MuSK, which is represented by the slightly slower migrating band of the two bands running at the size of MuSK2xwt (Fig. 1C). We extended our interaction studies to the $\alpha$ subunit of CK2 since CK2 mainly acts as a tetrameric holoenzyme. Both subunits interacted with the intracellular domain of MuSK, but the interaction with the $\alpha$ subunits was much weaker (Fig. 1C). Next, we examined whether the interaction of MuSK with either CK $2 \alpha$ or CK $2 \beta$ takes place in the presence of both CK2 subunits. This would indicate nonoverlapping binding epitopes for CK2 $\alpha, C K 2 \beta$, and MuSK. Precipitation of CK2 $\beta$ in the presence of MuSK2xwt and CK2 $\alpha$ led mainly to the coprecipitation of the tyrosine-phosphorylated form of MuSK2xwt (Fig. 1D). Further, if we precipitated MuSK2xwt from cells coexpressing both CK2 subunits, we could coprecipitate CK2 $\alpha$ (Fig. 1E). These experiments demonstrate an interaction between MuSK and the CK2 regulatory or catalytic subunit regardless of the coexpression of the other CK2 subunit. We then asked if the interaction between the CK $2 \alpha$ and CK2 $\beta$ 
A

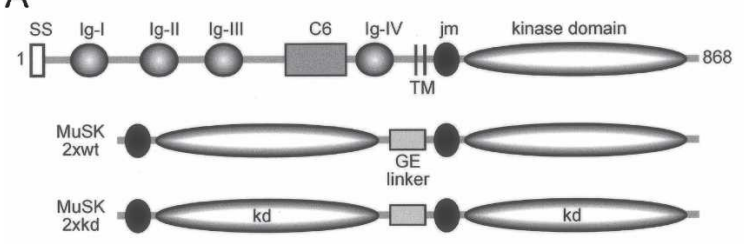

B
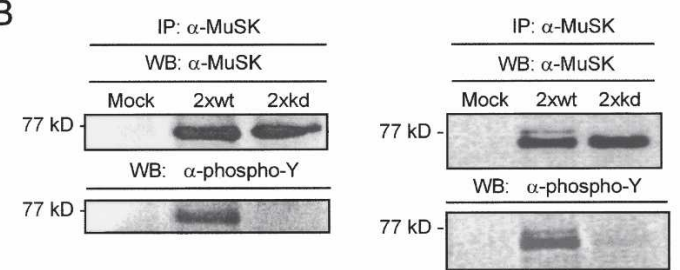

C
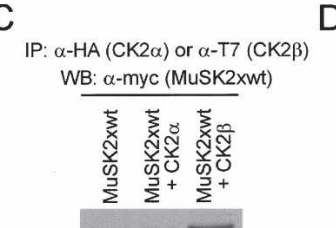

$64 \mathrm{kD}$ -

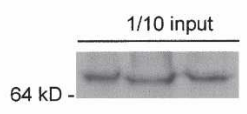

$\mathrm{F}$
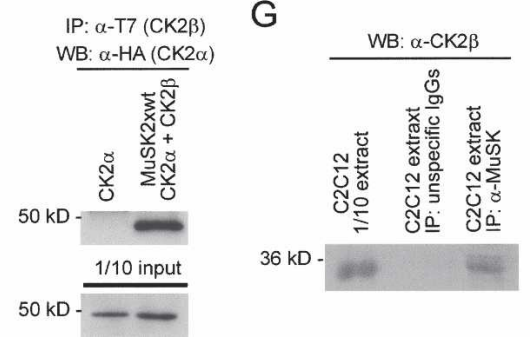

H

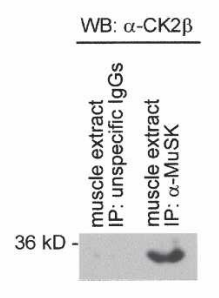

Figure 1. CK2 interacts with MuSK. (A) Constructs used for baits in the yeast two-hybrid screen. They are composed of two MuSK wild-type or kinase-deficient intracellular domains fused by a flexible GE linker (MuSK2xwt, MuSK2xkd). Autophosphorylation-dependent interaction with candidates was investigated with the bait containing kinase-defective MuSK domains (MuSK2xkd). (B) Detection of MuSK2xwt and MuSKx2kd protein expression in yeast (left panel) and Cos7 cells (right panel) by Western blot. Note that only MuSK2xwt is autophosphorylated. $(C-H)$ Interaction between MuSK and CK2 was investigated in detail by binding studies with extracts from transiently transfected HEK293 cells or cells expressing both proteins endogenously. Western blots are shown for coimmunoprecipitation of (1) MuSK2xwt by either CK2 $\alpha$ or CK2 $\beta(C),(2)$ MuSK $2 x w t$ by CK2 $\beta$ in the presence of CK $2 \alpha(D),(3)$ CK2 $\alpha$ by MuSK $2 x w t$ in the presence of CK2 $\beta(E),(4)$ CK $2 \alpha$ by CK $2 \beta$ in the presence of MuSK2xwt $(F)$, and (5) CK2 $\beta$ by MuSK using extract either from nerve-derived Agrin-treated C2C12 myotubes $(G)$, or from the synaptic area of hindlimb muscles isolated from adult mice $(H)$. $G$ and $H$ show interactions between CK2 $\beta$ and MuSK with endogenous muscle proteins.

subunits is affected by the presence of MuSK. We observed coprecipitation of CK2 $\alpha$ by CK2 $\beta$, independently of the presence of MuSK (Fig. 1F). Finally, MuSK also

interacts with CK2 $\beta$ under physiological conditions as evidenced by coimmunoprecipitation of endogenous proteins from myotubes treated with neural Agrin (Fig. 1G) and from the synaptic regions of innervated muscles (Fig. 1H). Recently, several publications described CK1 proteins as important mediators of the Wnt pathway (Davidson et al. 2005; Swiatek et al. 2006). To test for potential binding of Wnt pathway members, we examined if (1) CK2 $\beta$ binds to Wnt receptors, or (2) CK1 proteins and MuSK interact with each other. Although we identified expression of almost all CK1 proteins and Wnt receptors in $\mathrm{C} 2 \mathrm{C} 12$ myoblast and myotubes, we ascertained the absence of any interaction except the interaction between CK2 $\beta$ and MuSK (see Supplementary Fig. 1).

We next determined the epitopes of the MuSK intracellular domain and of CK2 $\beta$ that interact with each other. First, we generated a number of C-terminal deletion constructs for both proteins to investigate their binding to the full-length interacting counterpart (Fig. 2A,B). We fused these deletion mutants to the Gal4DNA binding or Gal4 activation domain and looked for interaction by the yeast two-hybrid technique. MuSK2xwt, MuSK2xkd, and the intracellular domain of MuSK (MuSK-868) interacted with full-length CK2 $\beta$. Deletion of the PDZ-binding domain (MuSK-857) located at the very $\mathrm{C}$ terminus of MuSK did not abolish interaction with full-length $\mathrm{CK} 2 \beta$, but any further deletion prevented binding completely (Fig. 2C). On the other hand, all deletion mutants of CK2 $\beta$ failed to interact with MuSK2xwt (Fig. 2C). We confirmed these epitope mapping studies by GST pulldowns of MuSK2xwt from HEK293 extracts using the same CK2 $\beta$ deletion fragments fused to GST (Fig. 2D), or by coimmunoprecipitation of CK2 $\beta$ from HEK293 cell extracts containing deletion mutants of the intracellular MuSK domain (Fig. 2E).

\section{Localization of CK2 subunits at the NMJ}

Given that CK2 and MuSK interact physically and that MuSK is concentrated at the NMJ, we sought to determine the temporal and spatial expression profile of CK2 subunits in synaptic and extrasynaptic regions. By immunohistochemical staining of cross-sections of hindlimb muscles of mice, synaptic localization of CK2 $\beta$ was first detected at postnatal day 7 (P7) (Fig. 3A), whereas no CK2 $\beta$ staining was observed at earlier stages (embryonic day 18.5 [E18.5], P0; data not shown). At later stages, synaptic CK $2 \beta$ was always colocalized with BTX immunostained AChR clusters in all muscles examined; i.e., soleus, gastrocnemius, and extensor digitorum longus (EDL) (Fig. 3A,B). Whenever CK2 $\beta$ was colocalized with BTX, we could also detect colocalized CK2 $\alpha$ (Fig. 3B-E). CK2 immunoreactivity was localized, at least in part, in the post-synaptic membrane rather than the motor nerve terminal or the terminal Schwann cells. In adult muscles, it was maintained for at least $5 \mathrm{~d}$ following denervation when the nerve terminal has degenerated (Fig. 3C), and it was seen at nerve cell- and Schwann 
A

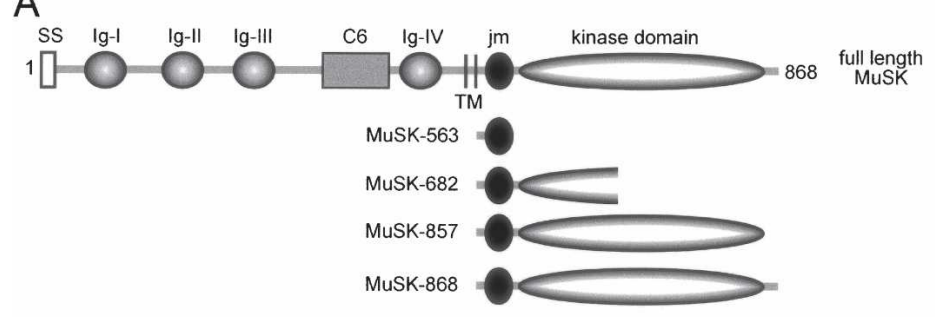

B

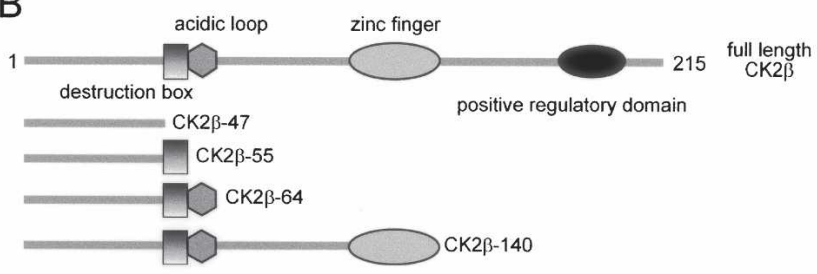

C

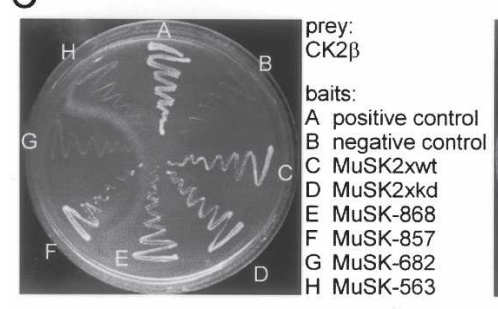

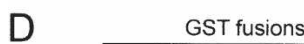

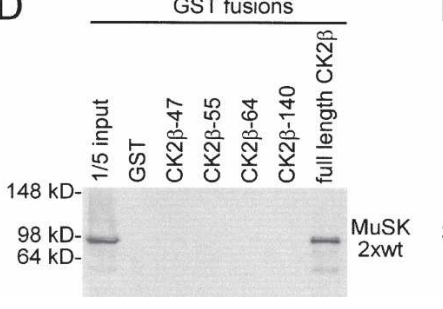

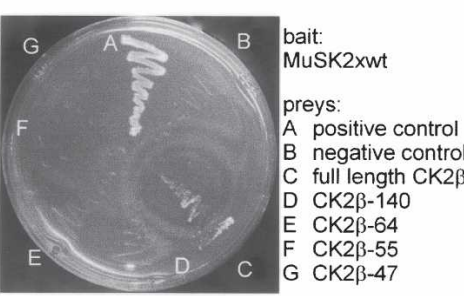

E

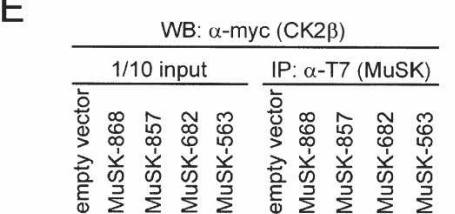

$36 \mathrm{kD}$ -
Figure 2. Mapping the interacting epitopes of MuSK and CK2 $\beta$. (A) C-terminal deletion constructs for the intracellular domain of MuSK, generated and subcloned either into a bait plasmid for yeast two-hybrid studies or into a CMV-driven expression plasmid for coimmunoprecipitations. $(B) \mathrm{C}$-terminal truncations of CK2 $\beta$, subcloned either into a prey plasmid for yeast two-hybrid studies or fused to GST for GST pulldown. (C) Yeast two-hybrid interactions were performed to identify the epitope of MuSK interacting with full-length CK2 $\beta$ (left panel) or the region of CK2 $\beta$ that associates with MuSK2xwt (right panel). (D) Recombinant GST fusion proteins containing different CK2 $\beta$ epitopes were incubated with extracts of HEK293 cells transiently transfected with MuSK2xwt. The ability of any of the GST fusion proteins to pull down MuSK2xwt was detected by Western blot. At the left, one-fifth of the input is shown. (E, right panel) Coimmunoprecipitation of CK2 $\beta$ by different intracellular MuSK epitopes detected by Western blot. One-tenth of the extract used as input for immunoprecipitation is shown on the left panel. Note that coprecipitation of CK2 $\beta$ requires at least the juxtamembrane region and the kinase domain of MuSK. cell-free ectopic post-synaptic membranes induced in vivo by recombinant Agrin (Fig. 3D; Meier et al. 1997; H.R. Brenner, unpubl.); in early postnatal (P14) muscles, when denervation leads to rapid loss of nerve terminals and Schwann cells (Trachtenberg and Thompson 1996), CK2 $\beta$ immunoreactivity remained localized to the synapse for at least $4 \mathrm{~d}$ after nerve section (Fig. 3E). While these experiments demonstrate that Agrin can recruit CK2 to the synapse, we do not know whether this involves synapse-specific transcription of the respective genes. Unlike for transcripts encoding, for example, AChR subunits or MuSK, quantitative RT-PCR of cDNA prepared from endplate bands of adult mouse diaphragm did not resolve significantly increased levels of CK2 transcripts (data not shown). With CK2 being ubiquitously expressed, weak synapse-specific expression may be obscured by transcripts from extrasynaptic segments inevitably contained even in carefully dissected endplate bands.

\section{CK2 phosphorylates serine residues of MuSK}

CK2 as a serine/threonine kinase might phosphorylate serine residues of the intracellular domain of MuSK. In- deed, a phosphorylated serine residue has been observed within the cytosolic part of MuSK (Till et al. 2002). In silico we identified four serines potentially phosphorylatable by CK2 within the KI of MuSK (Fig. 4A). To examine whether any of them are phosphorylated by CK2, we first determined in vitro CK $2 \alpha$-dependent incorporation of $\left[{ }^{32} \mathrm{P}\right] \gamma$-ATP into synthetic peptides with sequences corresponding to parts of the KI of MuSK, containing the four potentially phosphorylatable serine residues or alanine substitutions thereof.

The peptides bearing MuSK serine residues 680 or 697 incorporated high amounts of radioactivity (peptides MuSK667, MuSK667-S678A, MuSK687, MuSK687-S690A) (see Fig. 4B). In contrast, no incorporation was seen into peptides with respective alanine substitutions (peptides MuSK667-S680A, MuSK687-S697A) (Fig. 4B). Conspicuously, the peptides containing $\mathrm{S} 697$ show a higher degree of phosphorylation than peptides comprising $\mathbf{S} 680$ (Fig. 4B,C). We also determined the kinetics of serine phosphorylation with peptides representing parts of the MuSK KI. The higher incorporation of radioactivity into MuSK687, which contains S690 and S697, was reflected by a higher rate of phosphorylation of S697 than S680 (Fig. 4D). Finally, we examined whether this serine phos- 


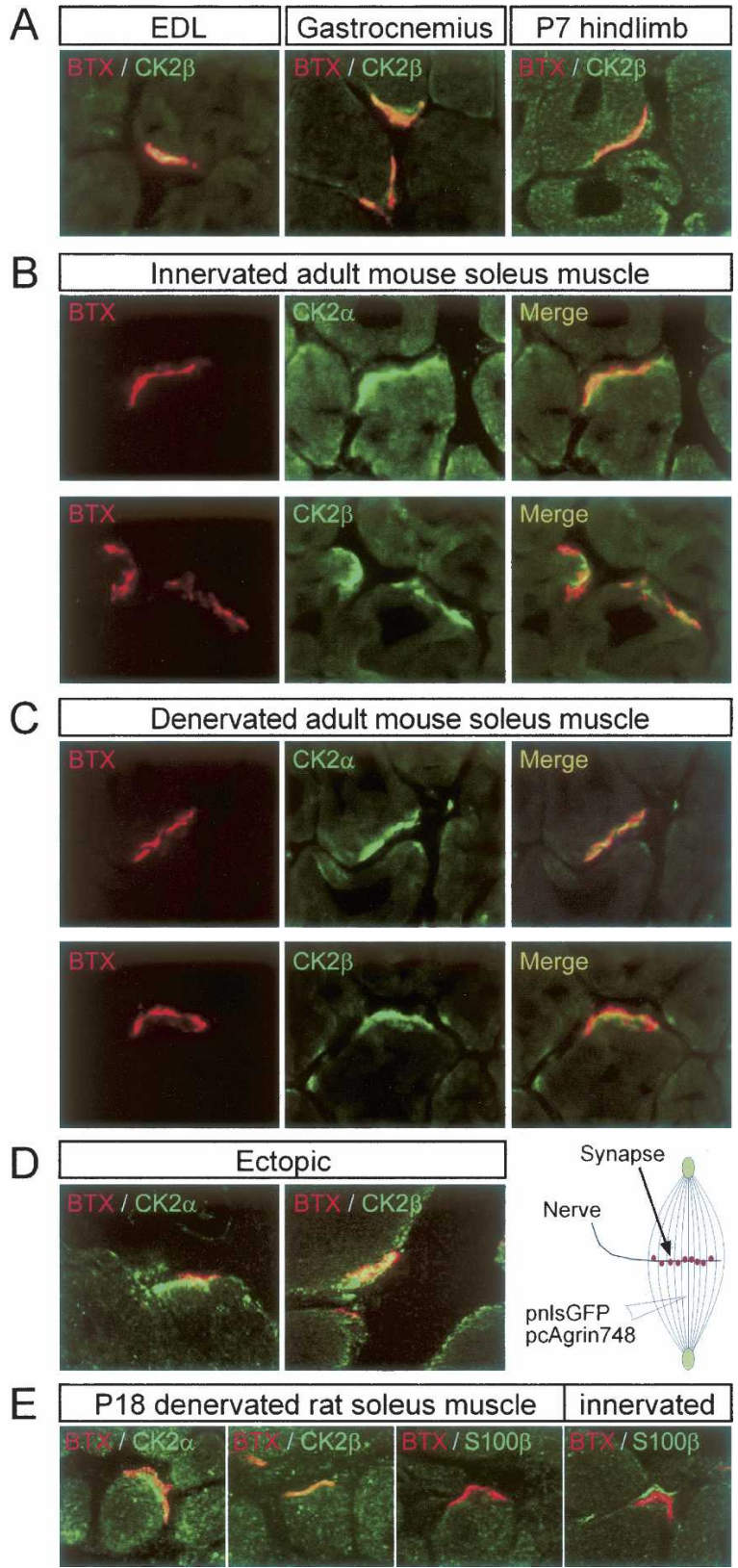

Figure 3. $\mathrm{CK} 2 \alpha$ and $\mathrm{CK} 2 \beta$ subunits colocalize with synaptic muscle membrane in vivo. (A) Typical images of cross-sections of mouse EDL, gastrocnemius, and unspecified early postnatal hindlimb muscle stained with BTX and CK2 $\beta$-reactive antibody as indicated. $(B, C)$ Images from innervated $(B)$ or surgically denervated $(C)$ contralateral mouse hindlimb muscle $5 \mathrm{~d}$ post-surgery, stained as indicated. Note the stability of synaptic CK2 $\alpha$ and CK2 $\beta$ localization upon loss of nerve terminal. $(D, E)$ CK2 is localized at least in part in subsynaptic muscle membrane. $(D)$ CK2 is resolved at Agrin-induced, ectopic postsynaptic membranes from rat soleus, which are nerve cell- and Schwann cell-free (generated by injection of Agrin expression plasmids). (E) CK2 is resolved in P18 mouse hindlimb muscle denervated $5 \mathrm{~d}$ earlier. Such endplates are known to lose Schwann cells. Note that in $A$ (only for P7), $D$, and $E$, images were obtained by confocal microscopy. phorylation occurred in the MuSK protein. To this end, we purified the intracellular domain of wild-type MuSK and of a respective serine-to-alanine replacement mutant and examined $\mathrm{CK} 2 \alpha$-dependent $\left[{ }^{32} \mathrm{P}\right] \gamma$-ATP incorporation. As with synthetic peptides, we observed phosphorylation of the wild-type intracellular domain of MuSK in the presence of CK2 $\alpha$ (Fig. 4E) that was, however, lower in the presence of the CK2 holoenzyme (Fig. $4 \mathrm{E})$. Again, the respective replacement of serines by alanines prevented incorporation of $\left[{ }^{32} \mathrm{P}\right] \gamma$-ATP by the CK2 catalytic subunit alone or together with the regulatory subunit (Fig. 4E).

Consistent with a functionally important role of S680 and S697, they are conserved in different species. The higher conservation of $\mathrm{S} 697$ correlates with its higher phosphorylation rate (Fig. 4B,F).

\section{Physiological role of CK2 at the NMJ}

The physiological role of CK2-mediated serine phosphorylation of MuSK on Agrin-induced AChR cluster formation was examined in $\mathrm{C} 2 \mathrm{C} 12$ myotubes. Treatment of these myotubes with nerve-derived Agrin induced AChR clusters (Fig. 5C). When CK2 activity was blocked by chemical inhibitors $(10-60 \mu \mathrm{M})$-like apigenin or DMAT (2-dimethylamino-4,5,6,7-tetrabromo$1 \mathrm{H}$-benzimidazole), the latter of which is highly selective for CK2 over CK1 (Critchfield et al. 1997; Pagano et al. 2004) - the number of Agrin-induced AChR clusters increased in a dose-dependent fashion by up to $\sim 2.5$ fold (Fig. 5A,C). However, the AChR clusters were smaller and highly dispersed (Fig. 5B,C), suggesting that serine phosphorylation in MuSK KI is important for normal AChR cluster formation and maintenance. Concentrations of CK2 inhibitors $>80 \mu \mathrm{M}$ were toxic.

The change in AChR cluster formation upon application of apigenin or DMAT was not due to impairment of MuSK kinase activity. In the presence of CK2 blockers, MuSK-dependent incorporation of $\left[{ }^{32} \mathrm{P}\right] \gamma$-ATP into the in vitro MuSK substrate enolase (Mohamed et al. 2001) was unchanged (Fig. 5D). But after application of CK2 blockers, we observed a significant decrease in the stability of $\mathrm{AChR}$ aggregates. The time course of the disappearance of AChR clusters upon removal of Agrin in C2C12 myotubes did not depend on the cotreatment with CK2 inhibitor. But further treatment with inhibitor after removal of Agrin resulted in much faster disappearance of AChR clusters (Fig. 5E).

Having found that S680 and S697 in the KI of MuSK are phosphorylated by CK2 (Fig. 4B), we next examined whether their phosphorylation affected AChR clustering. To this end, different MuSK mutants were made where the respective serines were substituted either by alanines that cannot be phosphorylated, or by aspartates or glutamates that mimic constitutive phosphorylation (Huffine and Scholtz 1996; Chung et al. 2003). Expression of these MuSK mutants was ascertained by transfection in HEK293 cells and Western blot (Fig. 6C). To compare their effects on AChR clustering, they were 
A

MuSK667

MuSK667-S678A

MuSK667-S680A

MuSK687

MuSK687-S690A

MuSK687-S697A

$B$
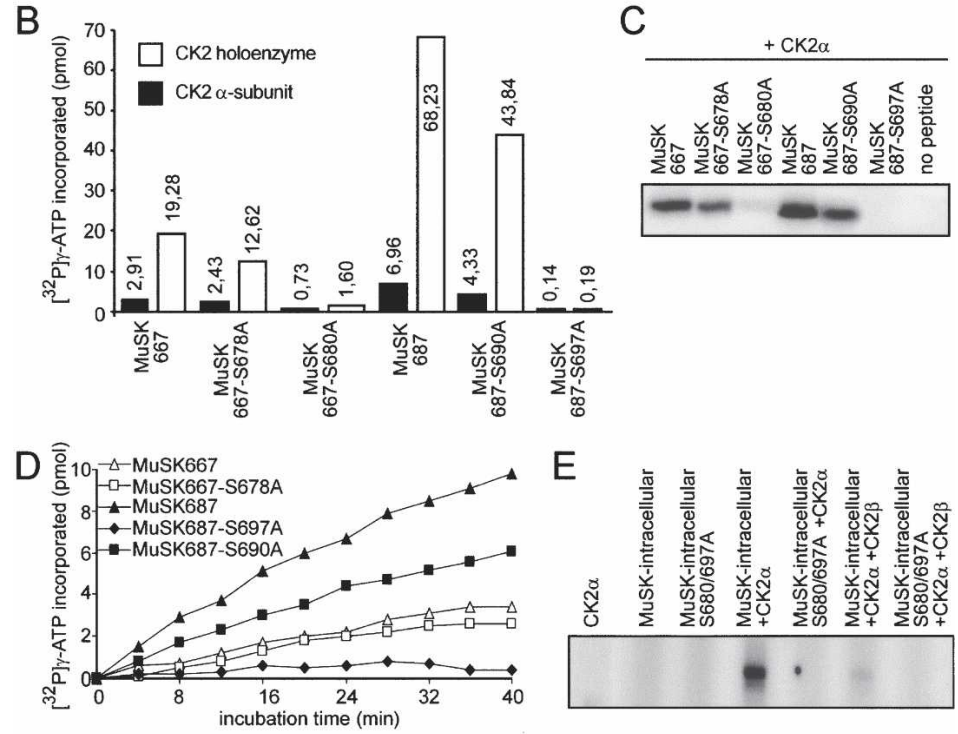

F

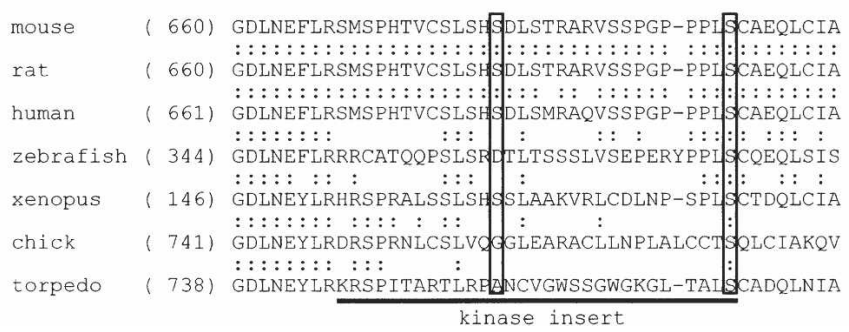

C

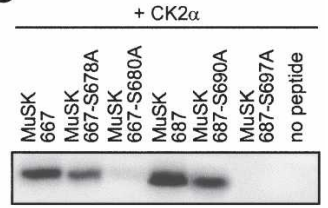

Figure 4. CK2 mediates phosphorylation of serine residues of MuSK. (A) Primary structure of synthetic peptides representing parts of the MuSK KI and containing potential CK2 phosphorylatable serine residues and the respective alanine substitutions. Numbering of peptides refers to the position of the amino acid residue of MuSK they start with. Peptides also containing alanine substitutions are specified. Potentially phosphorylatable serines are highlighted and shown in bold. $(B)$ In vitro $\left[{ }^{32} \mathrm{P}\right] \gamma$-ATP incorporation into peptides shown in $A$. Phosphorylation of peptides was performed with the catalytic CK2 subunit (black bars) or the CK2 holoenzyme (open bars). Amount of incorporated isotope is given as picomoles (indicated above or within bars). (C) After CK $2 \alpha$-mediated in vitro $\left[{ }^{32} \mathrm{P}\right] \gamma$-ATP incorporation, radiolabeled peptides were verified by SDS-PAGE and autoradiography. $(D)$ Kinetics of CK2-mediated in vitro phosphorylation of peptides presented in $A$. (E) Autoradiography of the purified recombinant wildtype intracellular part of MuSK and its S680/697A double mutant after in vitro phosphorylation by either CK $2 \alpha$ or the CK2 holoenzyme. Note that only the wildtype variant of the intracellular part of MuSK is phosphorylatable by CK2. (F) Alignment of amino acids of the KI region of MuSK from different species. Areas representing KIs are underlined, serine residues 680 and 697 are boxed. Note that $\mathrm{S} 697$ is conserved in all shown species.

transiently cotransfected with a nlsGFP expression plasmid into MuSK-deficient myoblasts (Herbst and Burden 2000), which were then allowed to differentiate into myotubes. In this way, interference by endogenous MuSK could be avoided, and transfected myotubes could be identified by GFP fluorescence. As a control, wildtype MuSK was transfected. During the last $16 \mathrm{~h}$ in culture, the myotubes were treated with nerve-derived Agrin in the presence or absence of the CK2 inhibitor DMAT. With wild-type MuSK expressed, we observed in the absence of DMAT the expected regular patches of AChR clusters. In the presence of DMAT AChR clusters were affected as described above (Fig. 6A). Upon transfection of MuSK constructs with alanine substitutions, AChR clusters were spotty and dispersed even in the absence of the inhibitor (Fig. 6A). When the serine residues were substituted by either aspartates or glutamates, AChR clusters appeared as focused dense patches, and they were not affected by the presence of the CK2 inhibitor DMAT (Fig. 6A). Changes in visual appearance of the AChR clusters were confirmed quantitatively by morphometrical analysis of the respective cluster areas (Fig. 6B). Together, these data strongly indicate a role for CK2-mediated phosphorylation of serine residues at po- sitions 680 and 697 within the intracellular part of MuSK in the regulation of AChR aggregation.

\section{Knockdown of CK2 impairs AChR clustering}

We further analyzed the requirement of CK2 activity for normal AChR clustering by separately knocking down the genes encoding each CK2 subunit, using CK2 $\alpha$-, $\mathrm{CK} 2 \alpha^{\prime}$-, and CK2 $\beta$-specific small interfering RNA (siRNA) molecules. Their efficacy on the mRNA and protein levels was ascertained (Fig. 7A-D,G,H). We then transiently transfected them into MuSK-deficient myotubes together with cDNAs encoding MuSK and GFP. siRNAs active against either CK2 $\alpha$ or CK $2 \alpha^{\prime}$ affected Agrin-induced AChR clusters in a similar way as did transfection of MuSK serine/alanine mutants (Figs. 6A, $7 \mathrm{E})$ or treatment with chemical inhibitors. Whereas ablation of only one of the two catalytic CK $2 \alpha$ subunits does not interfere with cell survival, transfection of siRNA active against both $\mathrm{CK} 2 \alpha$ and $\mathrm{CK} 2 \alpha^{\prime}$ or $\mathrm{CK} 2 \beta$ strongly reduced myoblast proliferation and fusion into myotubes (Fig. 7F,I), suggesting that catalytic CK2 activity is important for differentiation of cultured myotubes. 
Figure 5. Inhibition of CK2 activity affects AChR aggregation in cultured $\mathrm{C} 2 \mathrm{C} 12$ myotubes. Inhibitors of CK2 activity, apigenin, and DMAT (10-60 $\mu \mathrm{M})$ were applied to $\mathrm{C} 2 \mathrm{C} 12$ myotubes treated with nerve-derived Agrin. A further increase of inhibitor concentration was toxic for myotubes. (A) Number of AChR clusters was counted in three independent experiments and presented as percentage per $100 \times$ field. (B) A morphometrical analysis of AChR cluster length after treatment of $\mathrm{C} 2 \mathrm{C} 12$ myotubes with nerve-derived Agrin together with either apigenin or DMAT. Note that the number of smaller clusters is significantly increased. $(C)$ Representative images of BTX-stained (shown in red) myotubes incubated with DMSO, $60 \mu \mathrm{M}$ apigenin, or $40 \mu \mathrm{M}$ DMAT. Bar, $100 \mu \mathrm{m}$. (D) Autoradiography after performing a $\left[{ }^{32} \mathrm{P}\right] \gamma$-ATP incorporation assay with endogenous MuSK together with its in vitro substrate enolase. MuSK activity is induced after bath application of nerve-derived Agrin to $\mathrm{C} 2 \mathrm{C} 12$ myotubes, but is not affected by the presence of the CK2 inhibitor DMAT $(40 \mu \mathrm{M})$. (E) Measurement of AChR stability. The percentages of remaining BTX-stained AChR clusters are shown. For that, $\mathrm{C} 2 \mathrm{C} 12$ myotubes were treated with Agrin alone or together with apigenin for $16 \mathrm{~h}$ and then maintained in Agrin-free medium for indicated times, while apigenin was either still present or absent. Similar numbers were obtained using the CK2 inhibitor DMAT (data not shown). (*) $P$-values $<0.0003$.

\section{Deletion of the MuSK KI or its replacement by KIs of other receptor tyrosine kinases}

We identified in silico several serine residues of the KI of Platelet-Derived Growth Factor $\beta$ Receptor (PDGF $\beta-R)$ to undergo potential CK2-dependent phosphorylation (Fig. 8D). In contrast, the KIs of Insulin-like Growth Factor 1 Receptor (ILGF-1-R) and Insulin Receptor (IR) do not contain such phosphorylatable serine residues (Fig. 8D). To further corroborate a role of CK2-dependent serine phosphorylation of the MuSK KI in AChR clustering, we created a number of different MuSK mutants that lack the KI or in which the KI was replaced with that from PDGFß-R, ILGF-1-R, or IR. Expression of these mutant constructs was ascertained in HEK293 cells (Fig. 8C). Only when MuSK-deficient myotubes were transfected with the MuSK-PDGF $\beta$-R KI chimera bearing CK2 phosphorylatable serine residues did we observe regular AChR aggregation (Fig. 8A). In contrast, AChR clusters were not detected when a MuSK mutant lacking its KI was transfected (data not shown). Transfection of MuSK mutants carrying KIs from ILGF-1-R and IR led to spotty AChR clusters (Fig. 8A), as described above for impairment of CK2 function (Figs. 6A, 7E). Changes in visual appearance of the AChR clusters were confirmed quantitatively by morphometrical analysis of the respective cluster areas (Fig. 8B). These data further support the view that CK2-dependent phosphorylatable serines in
MuSK KI contribute to the formation of regular AChR clusters.

\section{Muscle-specific ablation of CK2 $\beta$ in mice impairs the maintenance of synaptic AChR clusters}

To examine whether CK2 $\beta$ is important for synaptic AChR clustering in vivo, we ablated the $C K 2 \beta$ gene selectively in muscle precursors. To this end, we bred mouse mutants with floxed exons within the $C K 2 \beta$ genomic locus (Buchou et al. 2003) and expressing Cre recombinase from E9 onward under the control of the human skeletal actin promoter (Schwander et al. 2003); i.e., before NMJs begin to form at E13. Mutant mice $\left(C K 2 \beta^{\operatorname{lox} P / / \operatorname{lox} P}, H S A-C r e\right)$ were born in the expected Mendelian ratio. Using the same transgene, previous experiments had demonstrated that Cre-dependent recombination is complete in all muscle nuclei (Escher et al. 2005). Consistent with muscle-specific deletion, CK2 $\beta$ was not detectable at synapses by immunofluorescence staining (data not shown). CK2 $\beta$ transcript levels in E18 and adult mutant muscles were significantly reduced but still detectable (Fig. 9F), as expected from the large ( 60\%) fraction of nonmuscle nuclei present in adult muscle (Escher et al. 2005). The mutant mice did not display an obvious phenotype within the first 2 mo of age. Over the next 4 mo, however, their grip strength, as measured by the 
A
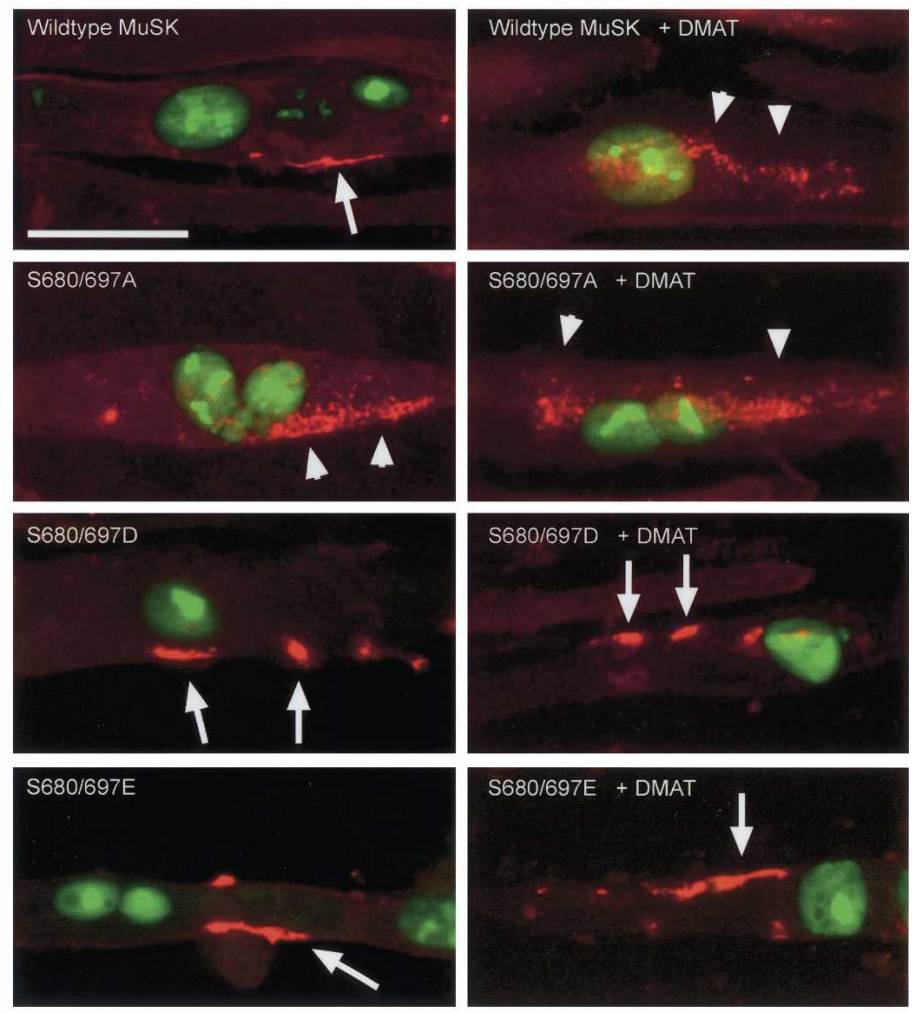

B

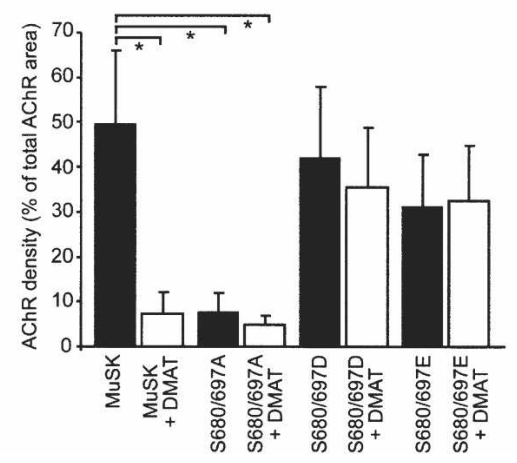

C

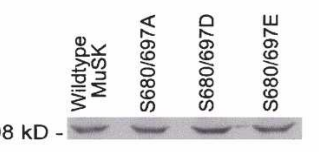

Figure 6. MuSK mutants with substitutions of phosphorylatable serines by alanines, aspartates, or glutamates contribute differently to AChR clustering. (A) Exemplary images from BTX-labeled MuSK-deficient myotubes that were transiently transfected with pnlsGFP and wild-type MuSK or different mutants thereof. Clustering of AChRs was induced by nervederived Agrin-containing conditioned medium. In addition, myotubes were coincubated with the CK2 inhibitor DMAT as indicated. Note that regular AChR clustering was impaired (arrowheads) if a S680/697A MuSK mutant was transfected in Agrin-treated cells, while regular AChR clusters (arrows) occurred on Agrintreated cells transfected with phosphorylation-imitating S680/697D or S680/697E MuSK mutants, even in the presence of the CK2 inhibitor. Same data were obtained using the CK2 inhibitor apigenin (data not shown). Bar, $50 \mu \mathrm{m}$. (B) Quantification of the effect shown in $A$ by presenting the AChR cluster density as described in the Materials and Methods. (*) $P$ values $<0.0001$. $(C)$ Expression of MuSK variants was confirmed by Western blot.

time for which they could cling upside-down to a wire grid, began to decline dramatically (grid test) (Fig. 9A), and body weight $(-5 \%-10 \%)$ was slightly reduced. The progressive weakness was accompanied by a significant decrease of miniature endplate currents (MEPC) of mutant muscles (Fig. 9B). In contrast, wild-type littermates retained their grip strength and MEPC amplitudes were unaltered. The vast majority of mutant NMJs at 6 mo revealed impaired morphological appearance of the synaptic AChR clusters. Specifically, the characteristic pretzel-like shape of age-matched wild-type endplates was dramatically fragmented in mutant muscles and began to further disintegrate into a spotty appearance (Fig. 9C). Interestingly, in spite of the fragmentation of the subsynaptic AChR clusters, the presynaptic terminal arborizations, as judged from immunostains for neurofilament, appeared largely intact even where postsynaptic AChR clusters had disintegrated into small spots (Fig. 9D). These changes were observed in all muscles examined; i.e., soleus, gastrocnemius, EDL, and diaphragm (data not shown). Surprisingly, measurement of CK2 kinase activity in wild-type and mutant mice of different age demonstrated a decline of kinase activity during aging in wild types (Fig. 9E). In CK2 $\beta$-ablated mutant muscles, CK2 kinase activity was higher than in wild-type mice but still declined proportionally during aging (Fig. 9E).

\section{Discussion}

The main results of this study are, first, that CK2 is concentrated in the subsynaptic muscle membrane and that CK2-mediated serine phosphorylation of the intracellular domain of the receptor tyrosine kinase MuSK is important for normal AChR aggregation and maintenance by Agrin in cultured myotubes and for the maintenance of synaptic AChR clusters in adult mice. When CK2 function is impaired, AChR aggregation is im- 
Figure 7. Knockdown of CK2 in cultured myotubes. Different siRNAs were examined regarding their ability to knockdown the mRNAs of different CK2 subunits by a luciferase-reporter assay. For that, bicistronic mRNAs bearing a full-length luciferase cDNA and the full-length cDNA encoding the respective CK2 subunit were created. $(A, C, G)$ Transient transfections into HEK293 cells were carried out using these constructs together with specific siRNAs active against the genes encoding CK2 subunits. $(B, D, H)$ The lack of the respective CK2 subunits at protein level was demonstrated after transient transfection in HEK293 cells by Western blot. Note that both $\mathrm{CK} 2 \alpha$ and $\mathrm{CK} 2 \alpha^{\prime}$ subunits are knocked down by the siRNA CK2 $\alpha^{\prime}-690$. (E) Typical images of BTX-stained (shown in red) Agrin-treated MuSK-deficient myotubes after transient transfection of wildtype full-length MuSK together with pnlsGFP and respective siRNAs (bar, 50 $\mu \mathrm{m})$. Note that formation of regular AChR clusters is significantly affected. Only very small and dispersed clusters form if the expression of the indicated CK2 $\alpha$ subunit is inhibited. $(F, I)$ Concomitant knockdown of both CK $2 \alpha$ and CK $2 \alpha^{\prime}$ or the CK $2 \beta$ subunit by siRNA corrupted cell survival countable by a strong decrease of GFPpositive MuSK-deficient cells.
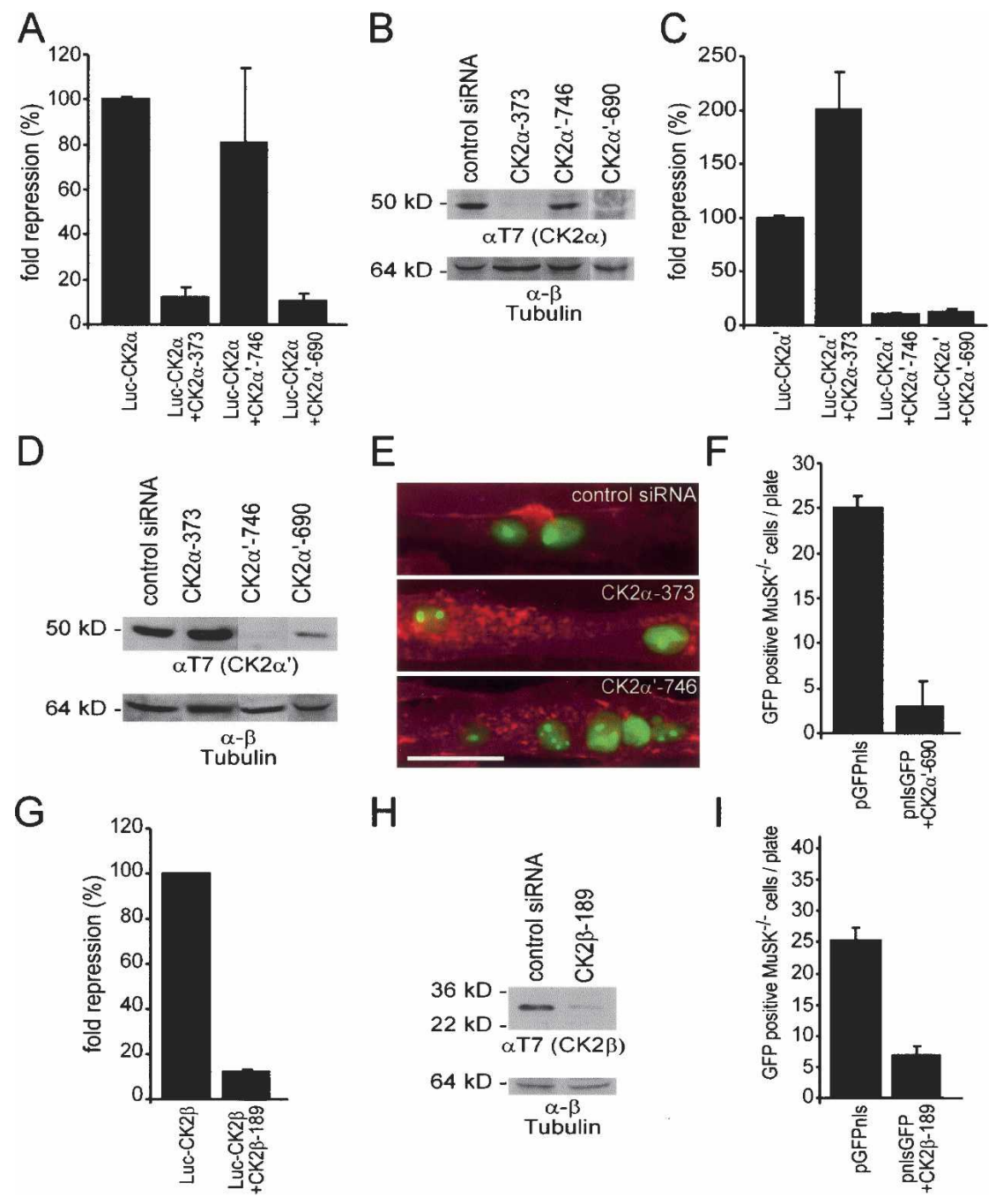

$\mathrm{H}$
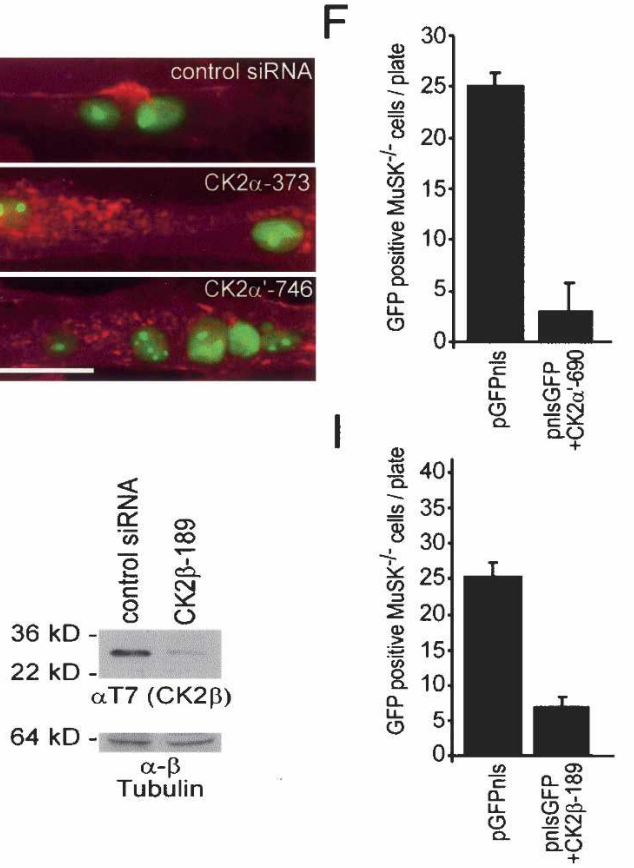

paired, as shown both by inhibitor and knockdown studies in cultured myotubes and by ablation of $C K 2 \beta$ in mouse muscle in vivo. In all cases, the number of AChR clusters significantly increased whereas their size decreased, resulting in fragmentation of Agrin- and nerveinduced AChR clusters. Second, we have identified a functional role of the KI of MuSK for the normal development of subsynaptic specializations.

In spite of the similar phenotypes of AChR clusters in myotubes in culture and at NMJs in vivo, they develop with strikingly different time courses: AChR clusters in myotubes disintegrate within hours upon blockade of CK2 activity or of knockdown of CK2 expression; in vivo, although synaptic CK2 expression is resolved only postnatally, synaptic AChR clusters develop normally, and, in $C K 2 \beta$ mutants, the first signs of neuromuscular impairment are barely detectable before P60.

The rapid disappearance of Agrin-induced AChR clusters in cultured myotubes in the presence of CK2 inhibitor (Fig. 5E) indicates a role for CK2 in stabilizing AChR aggregates. Consistent with such a role, synaptic AChR clusters are resistant to denervation at adult endplates, when synaptic CK2 is resistant to denervation, but are rapidly dispersed when nerves are sectioned in neonates (Slater 1982); i.e., before CK2 is first observed at the synapses.

There are several plausible but, at present, no definitive explanations for the difference in time course with which Agrin-induced AChR clusters in cultured myotubes and nerve-induced AChR clusters in vivo are fragmented when CK2 function is impaired. First, we observed fragmentation of AChR clusters in cultured myotubes after inhibition of CK2 activity or knockdown of $C K 2 \alpha$. In our $C K 2 \beta$ mutant mice, however, the CK $2 \alpha$ subunits mediating the kinase activity are still present, and kinase activity is increased. Second, at the NMJ, Agrin may not be the only neural signal contributing to the stability of synaptic AChR clusters, as suggested by the recent observations that $\mathrm{AChR}$ clusters form readily at neuromuscular contact sites in ChAT/agrin-deficient mice (Lin et al. 2005; Misgeld et al. 2005). Thus, nerveinduced AChR clusters may be more resistant to deprivation of CK2 than Agrin-induced AChR clusters. Third, in the CK2 $\beta$ mutant mice, we observed at P30-P240 a three- to sixfold increase in CK2 kinase activity compared with wild-type littermates (Fig. 9E), the reason for 


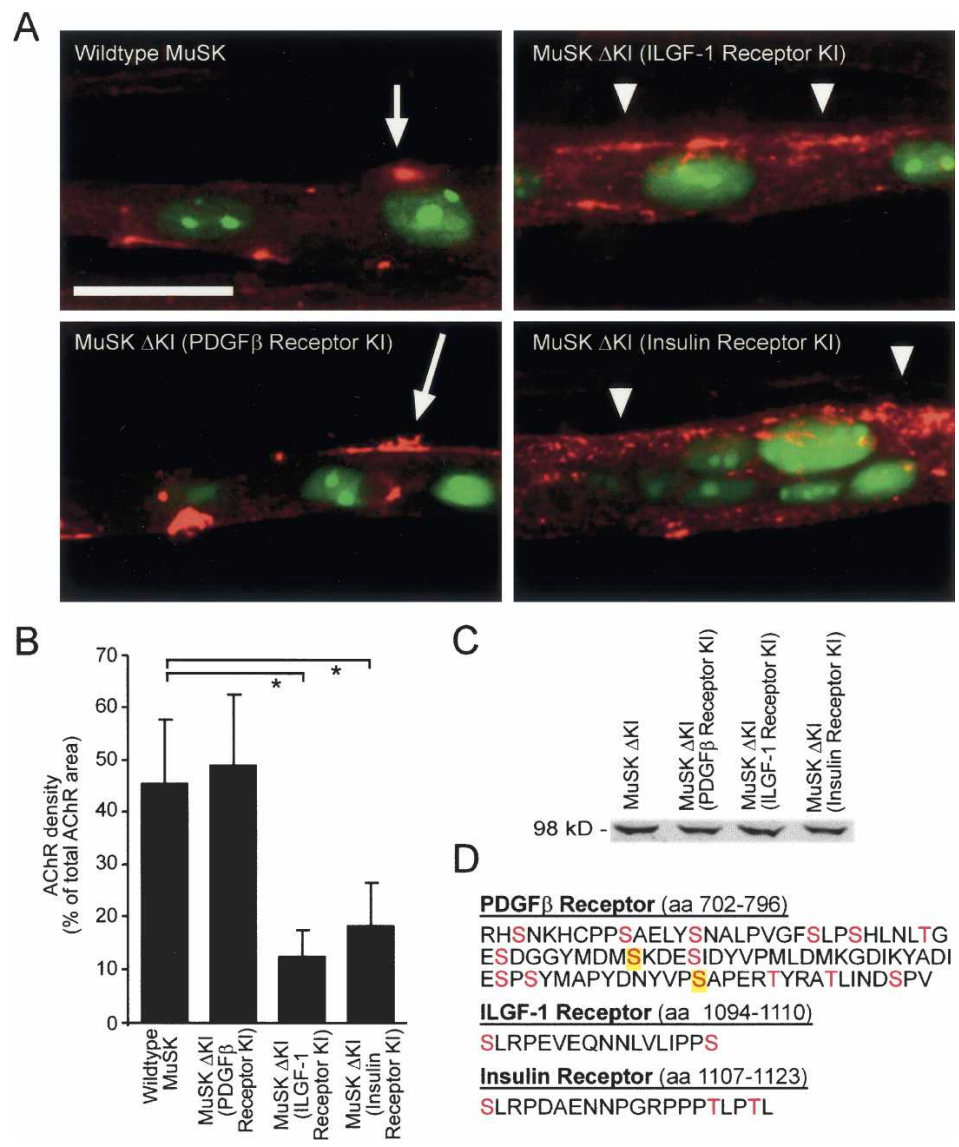

Figure 8. Replacement of the KI epitope of MuSK by that of PDGF $\beta-R$, ILGF-1-R, or IR. (A) Images represent typical patterns observed after transient transfection of MuSK-deficient myotubes with wild-type MuSK or with different MuSK KI mutants and subsequent immunostaining with BTX (shown in red). Note that regular formation of AChR clusters (arrows) occurred only after transfection of wild-type MuSK and of a mutant where the KI of MuSK was replaced by the KI of the PDGF $\beta$-R. Affected AChR clustering (arrowheads) was observed if the KI of MuSK was replaced by the KI of either ILGF-1-R or IR. Transfection of a MuSK where the original KI was deleted was unable to promote any AChR clustering after treatment with Agrin (data not shown). Bar, $50 \mu \mathrm{m}$. (B) Quantification of the effect shown in $A$ as described for Figure 6B. $\left(^{*}\right) P$-values $<0.004$. (C) Expression of MuSK KI mutants in HEK293 cells was confirmed by Western blot. (D) Amino acid residues of the KIs of PDGF $\beta$-R, ILGF-1-R, and IR are depicted. All serine and threonine residues are shown in red. Potential CK2 phosphorylatable serine or threonine residues are also highlighted. which is not known. However, both in mutants and wild types, CK2 activity declined with age. On the other hand, MuSK appears to interact more strongly with $\mathrm{CK} 2 \beta$ than with $\mathrm{CK} 2 \alpha$ (see coimmunoprecipitations in Fig. $1 \mathrm{C})$, suggesting that $\mathrm{CK} 2 \beta$ recruits $\mathrm{CK} 2 \alpha$ to the intracellular domain of MuSK. If so, the decrease in the recruitment of $\mathrm{CK} 2 \alpha$ to MuSK due to CK2 $\beta$ ablation could be compensated at younger, but not at older, ages by the increased CK $2 \alpha$ activity. Fourth, the subsynaptic apparatus of mature endplates is structurally more differentiated and stable than Agrin-induced AChR clusters in myotubes, which may add to the higher resistance of synaptic AChR clusters to CK2 $\beta$ removal (Lupa and Caldwell 1991).

The second major finding of the present work is that to our knowledge MuSK is one of the rare cases, next to, for example, the PDGF $\beta$ Receptor (Ullrich and Schlessinger 1990), in which a functional role of the KI could be documented. Evidence for this is that, first, the KI of MuSK appeared to be the most promising epitope in view of spatial accessibility due to its irregular end exposed conformation as suggested by the three-dimensional structure of the intracellular domain of MuSK (Till et al. 2002; Strochlic et al. 2004). Second, peptide fragments of MuSK KI containing CK2 phosphorylatable serine residues are indeed phosphorylated by CK2 in vitro. Third, replacement of the identified CK2-phosphorylatable serine residues by nonphosphorylatable residues disturbed
AChR aggregation. Fourth, inhibition of CK2 kinase activity leads to disturbed AChR aggregation in cultured myotubes. Fifth, replacement of the same serine residues by phosphorylation-imitating residues made AChR aggregation resistant to treatment by CK2 inhibitors. Sixth, the KIs of other receptor tyrosine kinases were only able to replace the KI of MuSK if they contained CK2-phosphorylatable serine residues. The fact that a previously reported mouse bearing a MuSK where the entire kinase domain was replaced by the same KI-deficient domain of TrkA generates normal AChR aggregates (Herbst and Burden 2000; Herbst et al. 2002) might due to the lack of long-term studies with these mice.

For the most part, the functional roles of KIs in receptor function went so far undetected. In some cases, however, they were suggested to modulate receptor interactions with certain cellular substrates and thus to modulate their function (Ullrich and Schlessinger 1990). Consistent with this view, we did not observe a complete loss of AChR aggregation when we treated cultured myotubes with CK2 blockers or knockdown CK2 $\alpha$. Phosphorylation of serine residues at the MuSK KI might produce docking sites for certain intracellular proteins. Indeed, previous work has hinted at potential serine phosphorylation of the MuSK intracellular domain (Till et al. 2002; Strochlic et al. 2004). We now demonstrate that serine phosphorylation in MuSK KI has a functional role and that it is mediated by CK2. One protein recently 
Figure 9. Ablation of the $C K 2 \beta$ gene in vivo causes muscle weakness, fragmentation of synaptic AChR aggregation and a decline in subsynaptic ACh sensitivity. (A) Time for which $C K 2 \beta$ mutant mice $>60 \mathrm{~d}$ cling upside down onto a horizontal wire mesh is dramatically shorter than for wild-type animals. The test was discontinued after $120 \mathrm{sec}$. Means \pm SE $(N=6$ for each age). (B) Amplitude of MEPCs in diaphragms of CK2 $\beta$ mutants is significantly reduced (two-sided $t$-test). Means $\pm \mathrm{SE}$ from 12-14 endplates from two mutant and two wild-type mice, 155 and $170 \mathrm{~d}$ of age. Holding potential, $-70 \mathrm{mV}$; temperature, $22^{\circ} \mathrm{C}$. Similar MEPC rise times and decay time constants indicate comparable recording conditions in mutant and wildtype muscles. $(C)$ Confocal micrographs of mouse gastrocnemius endplates stained with BTX. Note varying degrees of fragmentation of synaptic AChR clusters in CK2 $\beta$ mutant muscles. For quantification, synaptic AChR aggregates were grouped according to the following criteria: (Type A) AChR aggregates appear as uninterrupted longitudinal structures. (Type B) AChR aggregates are longitudinal and circular. (Type C) All AChR aggregates are circular. (Type D) AChR aggregates consist of circular structures and small spotty AChR aggregates. Arrowheads point to circular structures; arrows point to small spotty AChR aggregates. At least 100 confocal images from each of four mutant and wild-type soleus and gastrocnemius muscles were grouped independently by three individuals according to the above criteria. Percentages of each type averaged from the individual assessments (mean \pm

A

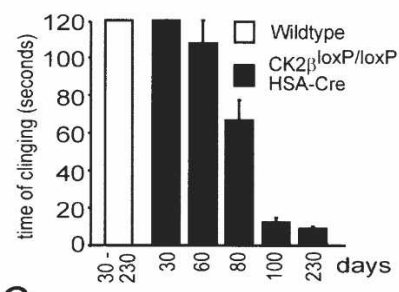

C
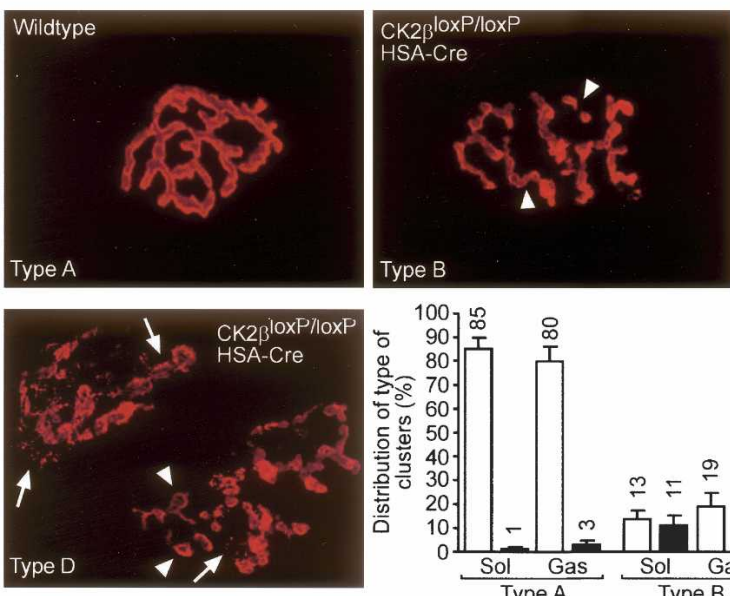

D

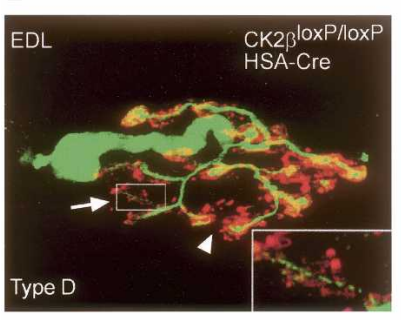

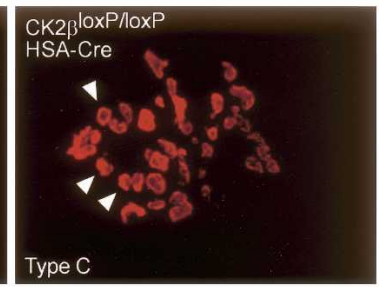

B

\begin{tabular}{|lccc|}
\hline Parameter & Wildtype & $\begin{array}{c}\text { CK2 } \beta \text { loxP/loxP } \\
\text { HSA-Cre }\end{array}$ & P-value \\
$\begin{array}{l}\text { MEPC amplitude (nA) } \\
\text { (two tailed t-test) }\end{array}$ & $\begin{array}{c}3.15+/-0.1 \\
(n=14)\end{array}$ & $\begin{array}{c}2.45+1-0.09 \\
(n=12)\end{array}$ & $<0.0001$ \\
$\begin{array}{l}\text { MEPC rise time ( } \mu \mathrm{s}) \\
(20-80 \%)\end{array}$ & $319+/-8$ & $333+/-7$ & 0.19 \\
$\begin{array}{l}\text { MEPC decay time } \\
\text { constant (ms) }\end{array}$ & $1.6+/-0.06$ & $1.7+/-0.04$ & 0.16 \\
\hline
\end{tabular}

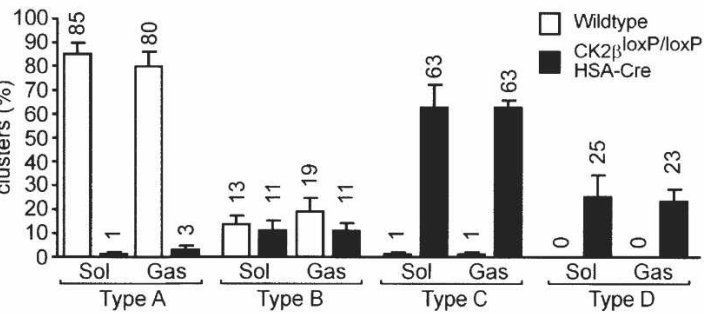

$\mathrm{E}$

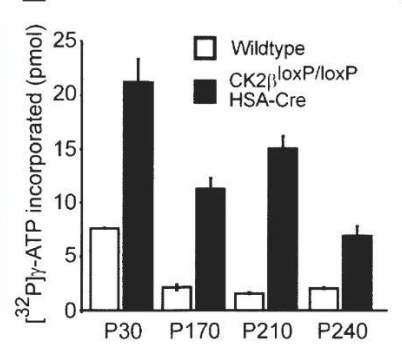

F

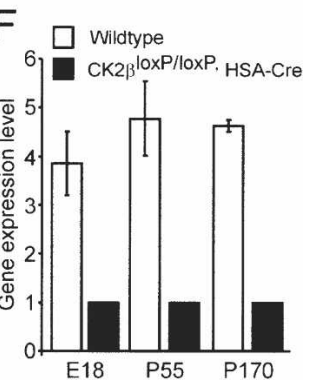

$\mathrm{SE}$ ) are given in the column graph. Note the prevalence of types C and D in mutant muscles (P210-P240), indicating AChR cluster fragmentation. $(D)$ Confocal image of EDL endplate stained for AChR and neurofilament immunoreactivity shows morphologically normal nerve terminal apposed by spotty subsynaptic AChR aggregates (arrows). Arrowheads indicate areas of AChR aggregations where no nerve is detectable. $(E)$ CK2 activity is increased in CK2 $\beta$ mutant compared with wild-type mice, but decreased with age. $(F)$ Reduction in CK2 $\beta$ transcript levels, measured by real-time RT-PCR, in mutant compared with wild-type muscle. The residual transcripts in the mutant originate from nonmuscle cells, which make up $\sim 60 \%$ of all nuclei in adult leg muscle.

shown to interact with MuSK in a serine phosphorylation-dependent manner, is 14-3-3y (Strochlic et al. 2004, 2005). 14-3-3 $\gamma$ is a member of a growing family of proteins involved in many intracellular signaling events, including MuSK signaling (Strochlic et al. 2004, 2005). Further studies will be required to elucidate a potential role of $\mathrm{CK} 2$ in this interaction.

In addition to CK2, other kinases are involved in AChR cluster stabilization. Recently, the Src family of kinases (Smith et al. 2001) and the Abelson tyrosine kinases (Abl) have been identified as MuSK effectors regulating stability (Finn et al. 2003). Since Abl kinases have been proposed to stabilize AChR clusters through induction of a synaptic actin network, the possibility of their involvement in CK2-dependent MuSK signaling should be investigated.
The Wnt pathway appears to be involved in the development of the NMJ in Drosophila and in presynaptic differentiation in the vertebrate CNS (Salinas 2005). Experimental evidence for its involvement in post-synaptic differentiation at the vertebrate NMJ is, so far, based on interactions between members of the Wnt/ $\beta$-catenin pathway, such as Dishevelled, APC, and $\beta$-catenin and proteins participating in the formation of post-synaptic specializations at the NMJ, such as MuSK, the $\beta$ subunit of AChRs, and rapsyn (Luo et al. 2002, 2003; Wang et al. 2003). Here, we did not observe a direct interaction between CK $2 \beta$ and Wnt transmembrane receptors or between MuSK and CK1, which has been recently invoked in Wnt signaling (see Supplementary Fig. 1; Davidson et al. 2005; Swiatek et al. 2006), suggesting that interactions between CK2 $\beta$ and MuSK are specific. However, 
CK2 and $\beta$-catenin have been shown to coprecipitate with the Dishevelled proteins (Song et al. 2000). CK2 phosphorylates $\beta$-catenin and Dishevelled proteins, and a CK2 inhibitor was shown to block proliferation of Wnttransfected cells by a reduction of $\beta$-catenin and Dishevelled levels (Song et al. 2000, 2003). In this way, CK2 could participate in both the Wnt/ $\beta$-catenin and the Agrin-MuSK signaling pathways. It remains to be seen whether the two pathways are connected.

The findings presented in this study might be of significant general impact regarding the fine-tuning of synaptogenesis not only at the NMJ but also in the CNS, where CK2 has already been detected (Chung et al. 2004). It is tempting to speculate that a number of signaling events mediated by receptor tyrosine kinases are influenced by either phosphorylation of serine residues within their KIs or other modifications that probably help to establish docking sites for intracellular signaling proteins.

\section{Materials and methods}

Plasmid constructs and yeast two-hybrid experiments

Two intracellular MuSK domains from rat (accession no. U34985) were linked together (named MuSK2xwt) by five modules that each coded for amino acid residues E and G. NcoI and EcoRI were used as restriction sites for the first intracellular MuSK domain; EcoRI and SalI were used for the second intracellular MuSK domain. The same strategy was applied for the generation of MuSK2xkd, representing two linked intracellular domains from a MuSK kinase-defective mutant. Both MuSK2xwt and MuSK2xkd were subcloned either in pGBKT7 (Clontech) to generate yeast two-hybrid bait plasmids or in myctagged pcDNA3 (Invitrogen) to create expression plasmids. Fulllength human CK2 $\beta$ fused in frame to Gal4 activation domain by use of restriction digestion sites EcoRI and XhoI into pGADGH was identified by a yeast two-hybrid screen. T7- or myctagged CMV-driven expression plasmids containing full-length CK2 $\beta$ were constructed by PCR amplification of CK2 $\beta$ cDNA and use of restriction digestion sites HindIII/XhoI or KpnI/ HindIII, respectively. For epitope-mapping studies, different yeast expression plasmids containing PCR-amplified intracellular epitopes of mouse MuSK (accession no. MMU37709)—starting with the first amino acid residue of the intracellular domain after the transmembrane segment-were subcloned into pGBKT7 using restriction digestion sites EcoRI and SalI. As a $5^{\prime}$ primer, 5'-GGAATTCTATTGCTGCCGAAGGAGGAAA$3^{\prime}$ was always used and was combined with the following $3^{\prime}$ primers for the different epitopes: (1) until the end of the juxtamembrane area (MuSK-563), 5'-ACGCGTCGACTTACTTGG GATTCAGAAGGA-3'; (2) until middle of the kinase domain (MuSK-682), 5' -ACGCGTCGACTTAGCGCTGCAGGATCCG GT-3'; (3) until the end of the kinase domain (MuSK-857), 5'ACGCGTCGACTTACAGGTCACTGTGGCTGA-3'; and (4) until the end of the MuSK protein (MuSK-868), 5'-ACGC GTCGACTTAGACGCCTACCGTTCCCA-3'. PCR-amplified human CK2 $\beta$-encoding epitopes (accession no. NM_001320) were fused to Gal4 activation domain using as vector pGAD424 (Clontech) and restriction sites BamHI and BglII. The 5' primer 5'-GGGGATCCGTATGAGCAGCTCAGAGGAG-3' was used with one of the following $3^{\prime}$ primers for four different CK2 $\beta$ epitopes: (1) CK2 $\beta-47,5$ '-GAAGATCTTTATCGGTAGTGA GGGACCTG-3'; (2) CK2 $\beta$-55, 5'-GAAGATCTTTAGTCCAA GATCATGTCTAG-3'; (3) CK2 $\beta$ - 64 , $5^{\prime}$-GAAGATCTTTAGTC TTCCAGTTCTTCATC-3'; and (4) CK2 $\beta$-140, 5'-GAAGATC
TTTAGCACTTGGGGCAGTAGAG-3'. Full-length and 3' truncated versions of human CK $2 \beta$ were amplified by PCR and fused to GST using the vector pGEX-KG (Guan and Dixon 1991) and restriction sites XhoI and HindIII. For that $5^{\prime}$ primer, $5^{\prime}$-CCG CTCGAGATGAGCAGCTCAGAGGAG-3' was combined with 3' primers (1) CK2 $\beta-47$, 5'-ATAAAGCTTTTATCGGTAGT GAGGGACCGT-3'; (2) CK2 $\beta$-55, 5'-ATAAAGCTTTTAGTC CAAGATCATGTCTAG-3'; (3) CK2 $\beta-64$, 5'-ATAAAGCTTT TAGTCTTCCAGTTCTTCATC-3'; (4) CK2 $\beta-140,5^{\prime}$-ATAAA GCTTTTAGCACTTGGGGCAGTAGAG-3'; and (5) full-length CK2 $\beta$, 5'-ATAAAGCTTTCAGCGAATCGTCTTGACTGG-3'. The The formation of hemagglutinin-tagged CK2 $\alpha$ as plasmid pCEFL-HA-CK $2 \alpha$ is described elsewhere (Korn et al. 2001). We fused CK2 $\alpha$ (accession no. BC072167) to a GST moiety by PCR amplification using the restriction digestion sites XhoI and HindIII of the plasmid pGEX-KG (primers 5'-CCGCTCGAGATGTCAG GACCTGTGCCAAG-3' and 5'-CCCAAGCTTCTACTGAGTG GCTCCAGCTG-3'). Construction of T7-tagged CMV-driven expression plasmids containing the intracellular domain of mouse MuSK (accession no. MMU37709) or 3' truncations thereof required first the insertion of the tag into pCMX-PL1 (Umesono et al. 1991). Thereafter, 5'-GGAATTCGTATTGCTGCCGAAG GAGGAAA-3' was used in combination with different 3 ' primers: (1) MuSK-563， 5'-CCGCTCGAGTTACTTAGGATTCAGAAG GAG-3'; (2) MuSK-682， 5'-CCGCTCGAGTTACAGGTCACT GTGGCTGAG-3'; (3) MuSK-857, 5'-CCGCTCGAGTTAGCGC TGCAGGATCCTGTG-3'; and (4) MuSK-868, 5'-CCGCTC GAGTTAGACACCCACCGTTCCCTC-3'. For generation of recombinant protein from Escherichia coli, the intracellular domain of MuSK from rat was amplified by PCR using primers $5^{\prime}$ CCCAAGCTTACCATGTATTGCTGCCGAAGGAGGAGAGA G-3' and 5'-GGCCTCGAGTTGCTCTAGCTCAAGAAATTCC -3 ', subcloned into pET28b (Dianova) using restriction sites XhoI and HindIII, and thereby fused to a histidine-tag.

Silencing of CK2 subunits was achieved by use of either synthetic or plasmid-derived siRNAs. siRNA primers were designed with the software Sfold (Ding et al. 2004). For knocking down gene expression of mouse CK2 $\alpha$ (accession no. BC060742), complementary primers, starting at position $373 \mathrm{bp}$ (5'-GATCCCCGTGTTTGAAGCCATCAACATTCAAGAGATG TTGATGGCTTCAAACACTTTTTGGAAA-3' and 5' ${ }^{\prime}$-AGCTT TTCCAAAAAGTGTTTGAAGCCATCAACATCTCTTGAAT GTTGATGGCTTCAAACACGGG-3') were hybridized and subcloned into pSUPERneoGFP (Oligoengine) using restriction sites HindIII and BglII. Gene expression of mouse CK2 $\alpha^{\prime}$ and CK2 $\beta$ were inhibited using synthetic siRNAs (stealth RNAi, Invitrogen). For CK2 $\alpha^{\prime}$ (accession no. BC057862), two synthetic siRNA were used corresponding to position $690 \mathrm{bp}, 5^{\prime}$-UAU CAUGCUCGCUAACAUGCAGCCC-3', and 746 bp, 5'-AUU CGAACAAGCUGGUCAUAGUUGU-3'. CK2 $\beta$ (accession no. BC003775) gene expression was silenced using a synthetic siRNA corresponding to position 189 bp, 5'-AGAAGAAUU CAUUACCACGGAGCCC-3'.

The efficiency of knockdown of respective CK2 gene expression at mRNA level was quantified by a gene reporter assay. Therefore, a luciferase gene and either CK $2 \alpha-$, CK $2 \alpha^{\prime}-$, or CK $2 \beta$ encoding cDNAs (see below) were subcloned as bicistronic messages into pCMX-PL1.

At protein level, the efficiency of knockdown of the respective CK2 subunits was confirmed by Western blot. Full-length $\mathrm{CK} 2 \alpha$ t, CK $2 \alpha^{\prime}-$, and CK2 $\beta$-encoding cDNAs from mouse were amplified by PCR, using following primers: CK2 $\alpha, 5$ '-CCG CTCGAGGATGTCGGGACCCGTGCCA- $3^{\prime}$ and 5'-GGGGT ACCTTACTGCTGAGCGCCAGC-3'; CK2 $\alpha^{\prime}$, 5'-CCCAAGCTT GATGCCCGGCCCGGCCGCG- ${ }^{\prime}$ and $5^{\prime}$-GGGGTACCTCAT CGTGCTGCGGTGAGAC-3'; or CK2 $\beta$, 5'-CCGCTCGAGGAT 
GAGTAGCTCTGAGGAG-3' and 5'-GGGGTACCTCAGCGA ATAGTCTTGAC-3', subcloned into pCMX-PL1-T7 linearized either by XhoI and KpnI (CK2 $\alpha, \mathrm{CK} 2 \beta)$ or HindIII and KpnI $\left(\mathrm{CK} 2 \alpha^{\prime}\right)$.

Substitutions of serine residues within the KI of MuSK by alanines, aspartates, or glutamates were introduced into plasmid pMT-MuSK (full-length MuSK; gift from Dr. Christian Fuhrer) or into plasmid pET28b-MuSK-intracellular, using the QuikChange XL Site-directed Mutagenesis Kit (Stratagene). All expression cassettes were verified by DNA sequencing. For detection of transfected cells in cell culture, a nuclear-localized version of GFP, pnlsGFP (Hashemolhosseini et al. 2000), was cotransfected.

For generation of pcDNA3-MuSK $\Delta$ KI lacking MuSK KI domain, the two parts upstream and downstream from the KI were separately amplified by PCR using for the upstream part primers 5'-CGAATTCATGAGAGAGCTTGTCAACATTC-3' and 5'CCCTAGGAACTCATTGAGGTCACCATAG-3' and for the downstream part primers 5'-GCCTAGGGTGTGCAGAACA GCTCTGC-3' and 5'-CTCTAGATTAGTATTGGTGAGGC CA-3'. Concomitantly, an AvrII site was introduced at the fusion site of both MuSK fragments. MuSK chimeras containing KIs of other receptor tyrosine kinases were generated using the AvrII site. ILGF-1-R (accession no. NM_010513) and IR (accession no. NM_010568) KIs were subcloned by hybridizing the following oligos: ILGF-1-R KI, 5'-CTAGCGTCTCTGAG GCCAGAAGTGGAGCAGAATAATCTAGTCCTCATTCCTC CGAGCTTC-3' and 5'-CTAGGAAGCTCGGAGGAATGAG GACTAGATTATTCTGCTCCACTTCTGGCCTCAGAGACG3'; and IR KI, 5'-CTAGCGTCTCTGAGGCCAGATGCTGAG AATAACCCAGGCCGCCCTCCCCCTACCTTGCAA-3' and 5'-CTAGTTGCAAGGTAGGGGGAGGGCGGCCTGGGTTATT CTCAGCATCTGGCCTCAGAGACG-3'. The KI of PDGFß-R (accession no. NM_008809) was amplified by PCR from mouse muscle first-strand cDNA, using following primers: 5'-AGC TAGCGCGACACTCCAACAAGCATTG-3' and 5'-GGCTAG CACTGGTGAGTCGTTGATTAAG-3'.

Yeast two-hybrid analysis was performed mainly according to the manufacturer's instructions (Clontech) and as previously described (Schubert et al. 2004).

\section{RNA preparation, reverse transcription, and PCR}

Total RNA was extracted from mouse tissues or from C2C12 cells with TRIzol reagent (Invitrogen) as described (Hashemolhosseini et al. 2002). After reverse transcription, cDNA was used for PCR with specific primers (see Plasmid Constructs) or with the following mouse-specific primer pairs for quantitative PCR reactions using the Lightcycler-FastStart DNA Master SYBR Green Kit and the Lightcycler Thermal Cycle System (Roche) according to the manufacturer's instructions: (1) CK2 $\beta$, 5'-TCTGTGAGGTGGATGAAGAC- ${ }^{\prime}$ ' and $5^{\prime}$-TGTGGATGCA CCATGAAGAG- $3^{\prime}$; and (2) $\beta$-actin, $5^{\prime}$-TGGAATCCTGTGG CATCCATGAAA- ${ }^{\prime}$ ' and $5^{\prime}$-TAAAACGCAGCTCAGTAACA GTCCG-3'

Tissue culture, transfection, extract preparation, Western blot, treatment with Agrin, application of CK2 inhibitors, quantification of AChR aggregates

Cos7 or HEK293 cells were maintained in Dulbecco's modified Eagle's medium (DMEM) containing 10\% (v/v) fetal calf serum (FCS, Invitrogen). C2C12 cells were maintained for proliferation in DMEM containing $20 \%(\mathrm{v} / \mathrm{v})$ FCS; for differentiation, the medium was replaced by DMEM with $5 \%(\mathrm{v} / \mathrm{v})$ heat-inactivated horse serum (HS, Invitrogen). Myotubes were formed after 4-6 d. MuSK-deficient myoblasts (gift from Drs. Ruth Herbst and Steve Burden) were proliferated in DMEM containing 10\% (v/v) FCS, $10 \%(\mathrm{v} / \mathrm{v}) \mathrm{HS}, 0.5 \%$ chick embryo extract (CEE, SLI), mouse recombinant interferon- $\gamma$ (Sigma) at $33^{\circ} \mathrm{C}$, and $10 \% \mathrm{CO}_{2}$. For differentiation, MuSK-deficient myoblasts were transferred to the proliferation medium lacking CEE and interferon- $\gamma$ at $39^{\circ} \mathrm{C}$ and $10 \% \mathrm{CO}_{2}$. For MuSK-deficient cells in all cases dishes were coated with Matrigel (Becton Dickinson). Myotubes were usually observed after 2-3 d.

For the preparation of cell extracts, HEK293 cells were transfected in $100-\mathrm{mm}$ dishes with a total of $10 \mu \mathrm{g}$ of expression vectors using Superfect (Qiagen), according to manufacturer's instructions (Hashemolhosseini et al. 2004). Cos7 cells were transfected in 100-mm plates for preparation of extracts using the DEAE-dextran technique followed by chloroquine treatment. The total amount of plasmid was always kept constant using empty CMV vector. At $48 \mathrm{~h}$ post-transfection, cells were harvested for extract preparation as described (Hashemolhosseini et al. 2004). For immunocytochemistry, C2C12 cells and MuSK-deficient cells were transfected in $35-\mathrm{mm}$ plates using Lipofectamin 2000 (Invitrogen), according to manufacturer's instructions, with $2 \mu \mathrm{g}$ of pnlsGFP together with $2 \mu \mathrm{g}$ of expression plasmid.

The production of Agrin-conditioned media was described previously (Kröger 1997). Agrin-conditioned medium was added at $1: 8$ dilution to $\mathrm{C} 2 \mathrm{C} 12$ myotubes. AChR aggregates were detected or quantified $16 \mathrm{~h}$ later, as described below. The terms active and inactive reflect Agrin originating either from isoform Agrin $_{\text {Аово }}$ or Agrin $_{\text {A4B8 }}$ (Gesemann et al. 1995).

For preparation of muscle tissue extract, synaptic areas of mouse soleus and gastrocnemius muscles were dissected, frozen in liquid nitrogen, mashed, and homogenized in ice cold lysis buffer (10 mM Hepes at pH 7.9, 0.2 mM EDTA, 2 mM DTT, 1\% Nonidet P-40, $2 \mu \mathrm{g} / \mu \mathrm{L}$ leupeptin and aprotinin) for $10 \mathrm{~min}$.

For detection of proteins on nitrocellulose membranes after Western blotting, the following primary antibodies were used: monoclonal antibodies directed against the T7-epitope (Novagen), myc-epitope (Cell Signaling), hemagglutinin-epitope (Santa Cruz), and against CK2 $\beta$ (gift from Dr. Olaf-Georg Issinger) or polyclonal sera against either CK2 $\alpha$ (Upstate Biotechnology) or MuSK (ABR, Abcam, or 194T gift from Dr. Markus Ruegg). Monoclonal antibodies were used at 1:10,000 or 1:250 dilutions (only for CK2 $\beta$ ); polyclonal antibodies were used at 1:100 dilution. Horseradish-peroxidase-coupled protein A or anti-mouse-Ig-coupled horseradish-peroxidase was used as secondary antibodies at 1:3000 dilution together with ECL detection system (Amersham).

Inhibition of endogenous CK2 activity was performed using one of two different inhibitors, either apigenin (Sigma, HCLP grade) or DMAT (Calbiochem and gift from Drs. Flavio Meggio and Lorenzo A. Pinna) (Critchfield et al. 1997; Pagano et al. 2004). Stock solutions for both inhibitors were generated by dissolving them in DMSO at $100 \mathrm{mM}$ or $10 \mathrm{mM}$, respectively. Four hours before adding of Agrin-conditioned media to C2C12or MuSK-deficient cells, apigenin was added to the cell cultivation medium at indicated concentrations. Twelve hours later, another $25 \%$ of apigenin was added to compensate for degradational loss of inhibitor activity. DMAT was added to the cell cultivation medium at the same time as Agrin-conditioned medium at indicated concentrations. For both inhibitors, cells were incubated in $16 \mathrm{~h}$ total with Agrin-conditioned medium. Same amounts of DMSO added to C2C12- or MuSK-deficient cells served as mock control. AChR aggregates were quantified as follows: Using the $\mathrm{Cy} 3$ filter, pictures were taken from 10 areas exhibiting similar myotube density as confirmed by phase contrast microscopy at $100 \times$ magnification. AChR clusters were 
counted for each area, normalized to mock treatment that was set to $100 \%$. Quantification of AChR clusters was performed for three independent experiments.

For assessing AChR cluster stability $\mathrm{C} 2 \mathrm{C} 12$ myotubes were treated for $16 \mathrm{~h}$ with Agrin alone or together with apigenin (60 $\mu \mathrm{M})$, washed, and then maintained in medium with or without apigenin. Cells were stained with 1:2500 diluted BTX (rhodamine- $\alpha$-bungarotoxin; $1 \mathrm{mg} / \mathrm{mL}$, Molecular Probes) at 0,4 , and 8 $\mathrm{h}$ and fixed in 4\% PFA. Number of AChR clusters at $0 \mathrm{~h}$ after Agrin removal was set to $100 \%$.

Quantification of the AChR cluster density and length was done as described before (Jacobson et al. 2001) using the Scion Image program (Scion Corporation). In brief, pictures of MuSKdeficient myotubes expressing AChR clusters on their surface were taken by fluorescence microscopy using the Cy3 filter. Images were imported into the Scion Image program in grayscale mode. Size scale calibration was set to 0.58 or 1.16 pixel/ $\mu \mathrm{m}$ for $400 \times$ and $200 \times$ magnification, respectively. The total cluster area was determined by circumscribing clusters using the free hand tool of the software and then measured. The clusters were highlighted using the density slice tool of the software. The selected areas were then compared with the original photographs, and the particles within the area occupied by clusters were analyzed. The quantifications were done independently by three individuals. The AChR density, given as a percentage, was calculated as particle area divided by total area of the cluster. The length of AChR clusters was presented in micrometers. Statistical analysis was performed using an unpaired two-tailed $t$-test.

For purification of recombinant proteins, plasmids carrying the histidine-tagged intracellular domain of MuSK from rat or its alanine mutant (S680/697A) were transformed in E. coli (BL21-Rosetta). The bacteria were grown until $\mathrm{OD}_{600}$ of 1.0, and the expression of the respective genes was induced by $1 \mathrm{mM}$ IPTG for $4 \mathrm{~h}$ to express the histidine-tag containing proteins. Bacterial pellets were dissolved after centrifugation in $6 \mathrm{M}$ guanidine hydrochloride, $0.1 \mathrm{M} \mathrm{NaH}_{2} \mathrm{PO}_{4}$, and $0.01 \mathrm{M}$ Tris (pH 8.5); shaken overnight at $250 \mathrm{rpm}$; and bound to Ni-NTA agarose beads (Qiagen) under constant rotation at RT. Beads were washed five times in $8 \mathrm{M}$ Urea, $0.1 \mathrm{M} \mathrm{NaH}_{2} \mathrm{PO}_{4}$, and $0.01 \mathrm{M}$ Tris (pH 8.0) and three times with $8 \mathrm{M}$ Urea, $0.1 \mathrm{M} \mathrm{NaH}_{2} \mathrm{PO}_{4}$, and $0.01 \mathrm{M}$ Tris $(\mathrm{pH}$ 6.6). Proteins were eluted with $8 \mathrm{M}$ Urea, $0.1 \mathrm{M} \mathrm{NaH}_{2} \mathrm{PO}_{4}$, and $0.01 \mathrm{M}$ Tris $(\mathrm{pH} 4.5)$ and concentrated using Centricon Plus-20 column (Amicon Bioseparations). Finally, proteins were dissolved in buffered conditions, and their final concentrations were adjusted to $200-500 \mathrm{ng} / \mu \mathrm{L}$.

\section{Immunoprecipitation and GST pulldowns}

For immunoprecipitations, transiently transfected HEK293 or Cos7 cells were lysed, and for each extract, the expression level of protein was analyzed by Western blot. One microliter of a monoclonal antibody against the T7 (Novagen), myc (Cell Signaling), or hemagglutinin epitope (SantaCruz) was added and the reaction incubated under constant rotation at $4^{\circ} \mathrm{C}$ for 30 min. Next, $20 \mu \mathrm{L}$ of PBS-equilibrated protein A-sepharose CL-4B beads (Amersham) was added and incubation was continued overnight. After washing the beads three times with HNTGbuffer (50 mM Hepes at $\mathrm{pH} 7.5,150 \mathrm{mM} \mathrm{NaCl}, 1 \mathrm{mM}$ EDTA, $10 \%$ glycerol, $0.1 \%$ Triton X-100, 10 mM PMSF, 1 mM leupeptin and aprotinin), the precipitated proteins were analyzed by SDS-PAGE and Western blot.

For GST pulldowns, bacteria were grown in $50-\mathrm{mL}$ cultures until $\mathrm{OD}_{600}$ was 0.4 and were induced by $1 \mathrm{mM}$ IPTG for $4 \mathrm{~h}$ to express the GST fusion proteins. Bacteria were collected by centrifugation, incubated in sonication buffer $\left(50 \mathrm{mM} \mathrm{NaH}{ }_{2} \mathrm{PO}_{4}\right.$,
$300 \mathrm{mM} \mathrm{NaCl}, 25 \mathrm{U} / \mathrm{mL}$ Benzonase, $10 \mu \mathrm{g} / \mathrm{mL}$ leupeptin, 10 $\mu \mathrm{g} / \mathrm{mL}$ aprotinin, $1 \mu \mathrm{L} / \mathrm{mL}$ Triton $\mathrm{X}-100,10 \mu \mathrm{g} / \mathrm{mL}$ DNAseI, 15 $\mathrm{U} / \mu \mathrm{L}$ Lysozym) for $30 \mathrm{~min}$ at $4^{\circ} \mathrm{C}$, lysed by sonication, and centrifuged. The supernatants containing the GST fusion proteins were supplemented by $30 \mu \mathrm{L}$ of equilibrated glutathione beads and incubated under constant rotation for $2 \mathrm{~h}$ at $4^{\circ} \mathrm{C}$. After washing three times with washing buffer $14.3 \mathrm{mM}$ $\mathrm{Na}_{2} \mathrm{HPO}_{4}, 1.47 \mathrm{mM} \mathrm{KH}_{2} \mathrm{PO}_{4}, 1.37 \mathrm{mM} \mathrm{NaCl}, 2.7 \mathrm{mM} \mathrm{KCl}$ ), an aliquot of the beads, now carrying the GST fusion protein, was incubated together with the extract from transiently transfected cells to pull down respective proteins. After washing the beads again three times with washing buffer, proteins bound to the beads were analyzed by SDS-PAGE and Western blot.

For immunoprecipitation of endogenous CK2 $\beta$ and MuSK proteins from $\mathrm{C} 2 \mathrm{C} 12$ cells or mouse soleus and gastrocnemius muscles, a polyclonal rabbit serum against MuSK (Abcam) was preconjugated with Protein A-sepharose and added to the extracts (Schubert et al. 2004). Samples were incubated under constant rotation overnight. After washing three times with $50 \mathrm{mM}$ Hepes (pH 7.5), $50 \mathrm{mM} \mathrm{NaCl}, 1 \mathrm{mM}$ EDTA, 10\% glycerol, 10 $\mathrm{mM}$ PMSF, and $1 \mathrm{mM}$ leupeptin and aprotinin, coprecipitated proteins were detected by SDS-PAGE and Western blot.

\section{$\left[{ }^{32} \mathrm{P}\right] \gamma$-ATP incorporation assay of peptides and proteins}

Peptides were custom synthesized (Thermo Electron). First, 0.2 $\mathrm{mM}$ of each peptide was incubated in $50 \mathrm{mM}$ Hepes buffer $(\mathrm{pH}$ 7.5), $10 \mathrm{mM} \mathrm{MgCl}_{2}, 0.5 \mathrm{mM}$ DTT, $50 \mathrm{mM} \mathrm{NaCl}$, and $50 \mu \mathrm{M}$ $\left[{ }^{32} \mathrm{P}\right] \gamma$-ATP (specific activity $3500-7800 \mathrm{cpm} / \mathrm{pmol}$ ) with different amounts of recombinant CK2 $\alpha$ from Xenopus laevis for 10 $\mathrm{min}$ (incorporation assay) or $30 \mathrm{~min}$ (verification by SDS-PAGE) at $30^{\circ} \mathrm{C}$ or for the indicated times (time course). For incorporation assays, either 3 or $4.5 \mathrm{pmol}$ of each peptide was used in the presence or absence of CK2 $\beta$. For time course assays, $33 \mathrm{pmol}$ of recombinant $\mathrm{CK} 2 \alpha$ from $X$. laevis was used; for verification of the phosphorylation by SDS-PAGE, $4.5 \mathrm{pmol}$ of recombinant $\mathrm{CK} 2 \alpha$ from $X$. laevis was used. In addition, the verification of the phosphorylation experiment by SDS-PAGE required $\left[{ }^{32} \mathrm{P}\right] \gamma-$ ATP with a specific activity of $20,000 \mathrm{cpm} / \mathrm{pmol}$. The reaction was spotted onto P81 phosphocellulose paper and washed three times in ice-cold $75 \mathrm{mM} \mathrm{H}_{3} \mathrm{PO}_{4}$. Paper-associated radioactivity was measured by scintillation counting. Control values obtained in assays without added enzyme were subtracted. For each peptide, the experiment was performed three times independently. For verification by SDS-PAGE, reactions were analyzed on $14 \%$ SDS-PAGE. Radioactive bands were detected on a Molecular Imager FX apparatus (Bio-Rad). CK2 activity of $10 \mu \mathrm{g}$ mouse muscle lysates was measured as described above using a previously described synthetic peptide substrate (RRRDDDSDDD).

For determining MuSK kinase activity, C2C12 myotubes were treated with Agrin and DMAT $(40 \mu \mathrm{M})$ as described (see above). From these cells, MuSK was isolated by immunoprecipitation using MuSK antibodies conjugated with Protein A-sepharose beads. Immunoprecipitates were washed three times in HNTG buffer, followed by two times washing in kinase buffer (10 $\mathrm{mM} \mathrm{MnCl}$, $50 \mathrm{mM}$ Tris at $\mathrm{pH}$ 7.4). After resuspension of the precipitated MuSK in kinase buffer acid, denatured enolase was added. The reaction was started by the addition of $\left[{ }^{32} \mathrm{P}\right] \gamma$ ATP, stopped after $10 \mathrm{~min}$ by addition of Laemmli buffer, and boiled for $5 \mathrm{~min}$, and the samples were resolved by $10 \%$ SDSPAGE for autoradiography. For acid denaturation of enolase, 1 vol of enolase was mixed with 1 vol of $50 \mathrm{mM}$ acetic acid and incubated for $5 \mathrm{~min}$ at $30^{\circ} \mathrm{C}$. Denaturation was stopped by addition of 1 vol of $1 \mathrm{M}$ Hepes (pH 7.4).

Recombinant intracellular domains of MuSK from rat or the 
respective alanine mutant thereof was phosphorylated in vitro by CK $2 \alpha$ ( 20 pmol; Biaffin) alone or together with CK2 $\beta$ (20 pmol; gift from Dr. Olaf-Georg Issinger) in $50 \mathrm{mM}$ Tris- $\mathrm{HCl}(\mathrm{pH}$ 8), $10 \mathrm{mM} \mathrm{MgCl}_{2}$, and $1 \mathrm{mM}$ DTT. After addition of $\left[{ }^{32} \mathrm{P}\right] \gamma$-ATP, samples were incubated for $30 \mathrm{~min}$ at $30^{\circ} \mathrm{C}$; the reactions were stopped by addition of Laemmli buffer, and samples were analyzed by SDS-PAGE and autoradiography.

Genotyping, electrophysiology, surgical procedures, tissue sections, immunohistochemistry, quantification of endplates

Mouse mating, genotyping, and electrophysiology were performed as described previously (Buchou et al. 2003; Schubert et al. 2004; Escher et al. 2005). For denervation experiments, animals were anesthetized by intraperitoneal administration of a ketamine-rompune mixture $(100 \mathrm{mg} / \mathrm{kg}$ body weight ketanest [Pfizer], $5 \mathrm{mg} / \mathrm{kg}$ body weight xylacin [Bayer]) for surgery using standard aseptic techniques. A skin incision was made on the lateral thigh to expose the left biceps femoris muscle, and a longitudinal incision was made to expose and transect the sciatic nerve at the level of its trifurcation. Animals were stitched and sacrificed after 4-5 d post-operatively, and their soleus and gastrocnemius muscle were dissected. Ectopic muscle injections of Agrin- and pnlsGFP-containing plasmids were performed as described before (Hashemolhosseini et al. 2000). For immunohistochemical analysis, all muscles were quick-frozen in prechilled isopentane and embedded in Tissue-Tec (Leica Instruments). Muscles were cryotome-sectioned to 12 - $\mu \mathrm{m}$ slices. Unfixed sections were rinsed with PBS and permeabilized for 5-10 min in PBS supplemented with $0.1 \%$ Triton X-100, blocked in $10 \%$ FCS and $1 \%$ BSA for 1-2 h. Cryotome sections were stained for AChR with BTX (1:2500 dilution of $1 \mathrm{mg} / \mathrm{mL}$ ) or incubated with rabbit anti-S100 $\beta$ (at 1:300 dilution; DAKO), anti-CK2 $\beta$ (at 1:500 dilution; gift from Drs. Mathias Montenarh or Claude Cochet), or anti-CK2 $\alpha$ antibody (at 1:1000 dilution; Upstate Biotechnology). Staining with anti-CK2 $\beta$ or anti-CK $2 \alpha$ antibody preincubated for $2 \mathrm{~h}$ with corresponding purified proteins served as a negative control. Secondary antibodies conjugated to Cy2 and Cy3 immunofluorescent dyes (Dianova) were used for detection.

For whole-mount preparations soleus (Sol), gastrocnemius (Gas), and EDL of wild-type and CK $2 \beta$ conditional knockout mice were isolated and fixed in $4 \%$ PFA. Thin bundles of teased muscles were blocked in $100 \mathrm{mM}$ glycine for $15 \mathrm{~min}$; permeabilized in $0.5 \%$ Triton X-100, 5\% BSA, and $1 \%$ FCS for $1 \mathrm{~h}$; and incubated with rabbit anti-Neurofilament antibody (at 1:5000 dilution; Chemicon). Secondary antibodies conjugated to Alexa488 (Molecular Probes) were applied together with BTX.

Sections were analyzed and documented using a Leica inverted microscope (DMIRB) equipped with a cooled MicroMax CCD camera (Princeton Instruments) or Leica confocal microscope TCS SL equipped by Leica confocal software TCS SL version 2.5.1347a. The confocal stacks were shown as average projections comprising several stacks taken with an interval of 0.5 $\mu \mathrm{m}$. Quantification of different AChR endplate types were performed by three independent individuals analyzing unknown BTX-immunostained muscle bundles, counting 100 endplates for each sample of muscle bundle and classifying them to different types (see Results).

\section{Acknowledgments}

We thank Christian Fuhrer for MuSK constructs; Claude Cochet, Olaf-Georg Issinger, Mathias Montenarh, and Markus Ruegg for providing CK $2 \alpha, \mathrm{CK} 2 \alpha^{\prime}, \mathrm{CK} 2 \beta$, and MuSK antibodies;
Ruth Herbst and Steve Burden for providing MuSK-deficient cells; Stephan Kröger for Agrin-releasing HEK293 cells; Lorenzo Pinna and Flavio Meggio for the CK2 inhibitor DMAT; and Michael Sendtner for help in performing ischiadicus lesions. We are indebted to Michael Wegner and Clarke Slater for critically reading the manuscript and numerous helpful comments. This work was supported by a grant from the Swiss National Science Foundation and the Swiss Foundation for Research on Muscle Diseases to H.R.B. and the Deutsche Forschungsgemeinschaft (DFG) to S.H. (HA 3309/1-1,2).

\section{References}

Buchou, T., Vernet, M., Blond, O., Jensen, H.H., Pointu, H., Olsen, B.B., Cochet, C., Issinger, O.G., and Boldyreff, B. 2003. Disruption of the regulatory $\beta$ subunit of protein kinase CK2 in mice leads to a cell-autonomous defect and early embryonic lethality. Mol. Cell. Biol. 23: 908-915.

Chung, H.J., Steinberg, J.P., Huganir, R.L., and Linden, D.J. 2003. Requirement of AMPA receptor GluR2 phosphorylation for cerebellar long-term depression. Science 300: 1751-1755.

Chung, H.J., Huang, Y.H., Lau, L.F., and Huganir, R.L. 2004. Regulation of the NMDA receptor complex and trafficking by activity-dependent phosphorylation of the NR2B subunit PDZ ligand. J. Neurosci. 24: 10248-10259.

Critchfield, J.W., Coligan, J.E., Folks, T.M., and Butera, S.T. 1997. Casein kinase II is a selective target of HIV-1 transcriptional inhibitors. Proc. Natl. Acad. Sci. 94: 6110-6115.

Dai, Z., Luo, X., Xie, H., and Peng, H.B. 2000. The actin-driven movement and formation of acetylcholine receptor clusters. J. Cell Biol. 150: 1321-1334.

Davidson, G., Wu, W., Shen, J., Bilic, J., Fenger, U., Stannek, P., Glinka, A., and Niehrs, C. 2005. Casein kinase $1 \gamma$ couples Wnt receptor activation to cytoplasmic signal transduction. Nature 438: 867-872.

Ding, Y., Chan, C.Y., and Lawrence, C.E. 2004. Sfold Web server for statistical folding and rational design of nucleic acids. Nucleic Acids Res. 32: W135-W141.

Escalier, D., Silvius, D., and Xu, X. 2003. Spermatogenesis of mice lacking CK2 $\alpha^{\prime}$ : Failure of germ cell survival and characteristic modifications of the spermatid nucleus. Mol. Reprod. Dev. 66: 190-201.

Escher, P., Lacazette, E., Courtet, M., Blindenbacher, A., Landmann, L., Bezakova, G., Lloyd, K.C., Mueller, U., and Brenner, H.R. 2005. Synapses form in skeletal muscles lacking neuregulin receptors. Science 308: 1920-1923.

Finn, A.J., Feng, G., and Pendergast, A.M. 2003. Postsynaptic requirement for Abl kinases in assembly of the neuromuscular junction. Nat. Neurosci. 6: 717-723.

Gesemann, M., Denzer, A.J., and Ruegg, M.A. 1995. Acetylcholine receptor-aggregating activity of agrin isoforms and mapping of the active site. J. Cell Biol. 128: 625-636.

Guan, K.L. and Dixon, J.E. 1991. Eukaryotic proteins expressed in Escherichia coli: An improved thrombin cleavage and purification procedure of fusion proteins with glutathione Stransferase. Anal. Biochem. 192: 262-267.

Hashemolhosseini, S., Moore, C., Landmann, L., Sander, A., Schwarz, H., Witzemann, V., Sakmann, B., and Brenner, H.R. 2000. Electrical activity and postsynapse formation in adult muscle: $\gamma$-AChRs are not required. Mol. Cell. Neurosci. 16: 697-707.

Hashemolhosseini, S., Hadjihannas, M., Stolt, C.C., Haas, C.S., Amann, K., and Wegner, M. 2002. Restricted expression of mouse GCMa/Gcml in kidney and thymus. Mech. Dev. 118: $175-178$. 
Hashemolhosseini, S., Schmidt, K., Kilian, K., Rodriguez, E., and Wegner, M. 2004. Conservation and variation of structure and function in a newly identified GCM homolog from chicken. J. Mol. Biol. 336: 441-451.

Heldin, C.H. 1995. Dimerization of cell surface receptors in signal transduction. Cell 80: 213-223.

Herbst, R. and Burden, S.J. 2000. The juxtamembrane region of MuSK has a critical role in agrin-mediated signaling. EMBO J. 19: 67-77.

Herbst, R., Avetisova, E., and Burden, S.J. 2002. Restoration of synapse formation in Musk mutant mice expressing a Musk/ Trk chimeric receptor. Development 129: 5449-5460.

Huffine, M.E. and Scholtz, J.M. 1996. Energetic implications for protein phosphorylation. Conformational stability of $\mathrm{HPr}$ variants that mimic phosphorylated forms. J. Biol. Chem. 271: 28898-28902.

Jacobson, C., Cote, P.D., Rossi, S.G., Rotundo, R.L., and Carbonetto, S. 2001. The dystroglycan complex is necessary for stabilization of acetylcholine receptor clusters at neuromuscular junctions and formation of the synaptic basement membrane. J. Cell Biol. 152: 435-450.

Korn, I., Jacob, G., Allende, C.C., and Allende, J.E. 2001. The activity of CK2 in the extracts of COS-7 cells transfected with wild type and mutant subunits of protein kinase CK2. Mol. Cell. Biochem. 227: 37-44.

Kröger, S. 1997. Differential distribution of Agrin isoforms in the developing and adult avian retina. Mol. Cell. Neurosci. 10: $149-161$.

Lacazette, E., Le Calvez, S., Gajendran, N., and Brenner, H.R. 2003. A novel pathway for MuSK to induce key genes in neuromuscular synapse formation. J. Cell Biol. 161: 727-736.

Lin, W., Dominguez, B., Yang, J., Aryal, P., Brandon, E.P., Gage, F.H., and Lee, K.F. 2005. Neurotransmitter acetylcholine negatively regulates neuromuscular synapse formation by a Cdk5-dependent mechanism. Neuron 46: 569-579.

Luo, Z.G., Wang, Q., Zhou, J.Z., Wang, J., Luo, Z., Liu, M., He, X., Wynshaw-Boris, A., Xiong, W.C., Lu, B., et al. 2002. Regulation of AChR clustering by Dishevelled interacting with MuSK and PAK1. Neuron 35: 489-505.

Luo, Z., Wang, Q., Dobbins, G.C., Levy, S., Xiong, W.C., and Mei, L. 2003. Signaling complexes for postsynaptic differentiation. J. Neurocytol. 32: 697-708.

Lupa, M.T. and Caldwell, J.H. 1991. Effect of Agrin on the distribution of acetylcholine receptors and sodium channels on adult skeletal muscle fibers in culture. J. Cell Biol. 115: 765-778.

McConville, J. and Vincent, A. 2002. Diseases of the neuromuscular junction. Curr. Opin. Pharmacol. 2: 296-301.

Meggio, F. and Pinna, L.A. 2003. One-thousand-and-one substrates of protein kinase CK2? FASEB J. 17: 349-368.

Meier, T., Hauser, D.M., Chiquet, M., Landmann, L., Ruegg, M.A., and Brenner, H.R. 1997. Neural agrin induces ectopic postsynaptic specializations in innervated muscle fibers. $J$. Neurosci. 17: 6534-6544.

Misgeld, T., Kummer, T.T., Lichtman, J.W., and Sanes, J.R. 2005. Agrin promotes synaptic differentiation by counteracting an inhibitory effect of neurotransmitter. Proc. Natl. Acad. Sci. 102: 11088-11093.

Mohamed, A.S., Rivas-Plata, K.A., Kraas, J.R., Saleh, S.M., and Swope, S.L. 2001. Src-class kinases act within the Agrin/ MuSK pathway to regulate acetylcholine receptor phosphorylation, cytoskeletal anchoring, and clustering. J. Neurosci. 21: 3806-3818.

Olsten, M.E. and Litchfield, D.W. 2004. Order or chaos? An evaluation of the regulation of protein kinase CK2. Biochem. Cell Biol. 82: 681-693.

Pagano, M.A., Meggio, F., Ruzzene, M., Andrzejewska, M., Ka- zimierczuk, Z., and Pinna, L.A. 2004. 2-Dimethylamino4,5,6,7-tetrabromo-1H-benzimidazole: A novel powerful and selective inhibitor of protein kinase CK2. Biochem. Biophys. Res. Commun. 321: 1040-1044.

Sadasivam, G., Willmann, R., Lin, S., Erb-Vogtli, S., Kong, X.C., Ruegg, M.A., and Fuhrer, C. 2005. Src-family kinases stabilize the neuromuscular synapse in vivo via protein interactions, phosphorylation, and cytoskeletal linkage of acetylcholine receptors. J. Neurosci. 25: 10479-10493.

Salinas, P.C. 2005. Retrograde signalling at the synapse: A role for Wnt proteins. Biochem. Soc. Trans. 33: 1295-1298.

Sanes, J.R. and Lichtman, J.W. 1999. Development of the vertebrate neuromuscular junction. Annu. Rev. Neurosci. 22: 389-442.

Schubert, S.W., Kardash, E., Khan, M.A., Cheusova, T., Kilian, K., Wegner, M., and Hashemolhosseini, S. 2004. Interaction, cooperative promoter modulation, and renal colocalization of GCMa and Pitx2. J. Biol. Chem. 279: 50358-50365.

Schwander, M., Leu, M., Stumm, M., Dorchies, O.M., Ruegg, U.T., Schittny, J., and Muller, U. 2003. $\beta 1$ integrins regulate myoblast fusion and sarcomere assembly. Dev. Cell 4: 673-685.

Slater, C.R. 1982. Postnatal maturation of nerve-muscle junctions in hindlimb muscles of the mouse. Dev. Biol. 94: 1122.

Smith, C.L., Mittaud, P., Prescott, E.D., Fuhrer, C., and Burden, S.J. 2001. Src, Fyn, and Yes are not required for neuromuscular synapse formation but are necessary for stabilization of Agrin-induced clusters of acetylcholine receptors. J. Neurosci. 21: 3151-3160.

Song, D.H., Sussman, D.J., and Seldin, D.C. 2000. Endogenous protein kinase CK2 participates in Wnt signaling in mammary epithelial cells. J. Biol. Chem. 275: 23790-23797.

Song, D.H., Dominguez, I., Mizuno, J., Kaut, M., Mohr, S.C., and Seldin, D.C. 2003. CK2 phosphorylation of the armadillo repeat region of $\beta$-catenin potentiates Wnt signaling. J. Biol. Chem. 278: 24018-24025.

Strochlic, L., Cartaud, A., Mejat, A., Grailhe, R., Schaeffer, L., Changeux, J.P., and Cartaud, J. 2004. 14-3-3 $\gamma$ associates with muscle specific kinase and regulates synaptic gene transcription at vertebrate neuromuscular synapse. Proc. Nat1. Acad. Sci. 101: 18189-18194.

Strochlic, L., Cartaud, A., and Cartaud, J. 2005. The synaptic muscle-specific kinase (MuSK) complex: New partners, new functions. Bioessays 27: 1129-1135.

Swiatek, W., Kang, H., Garcia, B.A., Shabanowitz, J., Coombs, G.S., Hunt, D.F., and Virshup, D.M. 2006. Negative regulation of LRP6 function by CKI $\varepsilon$ phosphorylation. I Biol Chem. 281: 12233-12241.

Till, J.H., Becerra, M., Watty, A., Lu, Y., Ma, Y., Neubert, T.A., Burden, S.J., and Hubbard, S.R. 2002. Crystal structure of the MuSK tyrosine kinase: Insights into receptor autoregulation. Structure (Camb.) 10: 1187-1196.

Trachtenberg, J.T. and Thompson, W.J. 1996. Schwann cell apoptosis at developing neuromuscular junctions is regulated by glial growth factor. Nature 379: 174-177.

Ullrich, A. and Schlessinger, J. 1990. Signal transduction by receptors with tyrosine kinase activity. Cell 61: 203-212.

Umesono, K., Murakami, K.K., Thompson, C.C., and Evans, R.M. 1991. Direct repeats as selective response elements for the thyroid hormone, retinoic acid, and vitamin D3 receptors. Cell 65: 1255-1266.

Wang, J., Jing, Z., Zhang, L., Zhou, G., Braun, J., Yao, Y., and Wang, Z.Z. 2003. Regulation of acetylcholine receptor clustering by the tumor suppressor APC. Nat. Neurosci. 6: 1017-1018.

Watty, A., Neubauer, G., Dreger, M., Zimmer, M., Wilm, M., and Burden, S.J. 2000. The in vitro and in vivo phosphotyrosine 
Cheusova et al.

map of activated MuSK. Proc. Nat1. Acad. Sci. 97: 4585-4590.

Weston, C., Yee, B., Hod, E., and Prives, J. 2000. Agrin-induced acetylcholine receptor clustering is mediated by the small guanosine triphosphatases Rac and Cdc42. J. Cell Biol. 150: 205-212.

Weston, C., Gordon, C., Teressa, G., Hod, E., Ren, X.D., and Prives, J. 2003. Cooperative regulation by Rac and Rho of agrin-induced acetylcholine receptor clustering in muscle cells. J. Biol. Chem. 278: 6450-6455.

Xu, X., Toselli, P.A., Russell, L.D., and Seldin, D.C. 1999. Globozoospermia in mice lacking the casein kinase II $\alpha^{\prime}$ catalytic subunit. Nat. Genet. 23: 118-121.

Zhou, H., Glass, D.J., Yancopoulos, G.D., and Sanes, J.R. 1999. Distinct domains of MuSK mediate its abilities to induce and to associate with postsynaptic specializations. J. Cell Biol. 146: 1133-1146.

Zou, Y. 2004. Wnt signaling in axon guidance. Trends Neurosci. 27: 528-532. 


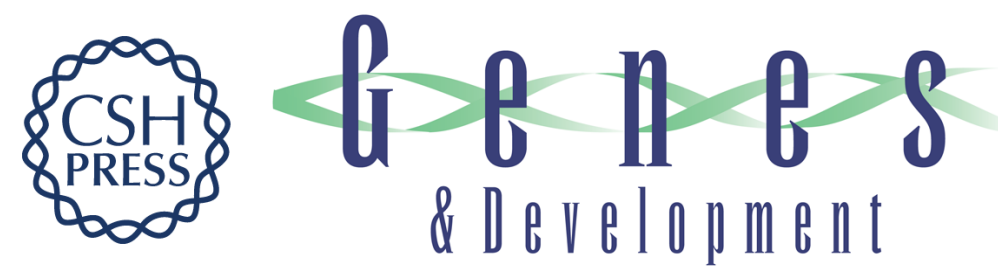

\section{Casein kinase 2-dependent serine phosphorylation of MuSK regulates acetylcholine receptor aggregation at the neuromuscular junction}

Tatiana Cheusova, Muhammad Amir Khan, Steffen Wolfgang Schubert, et al.

Genes Dev. 2006, 20:

Access the most recent version at doi:10.1101/gad.375206

Supplemental http://genesdev.cshlp.org/content/suppl/2006/06/09/20.13.1800.DC1
Material

References This article cites 57 articles, 27 of which can be accessed free at:

http://genesdev.cshlp.org/content/20/13/1800.full.html\#ref-list-1

License

Email Alerting Receive free email alerts when new articles cite this article - sign up in the box at the top

Service

right corner of the article or click here.

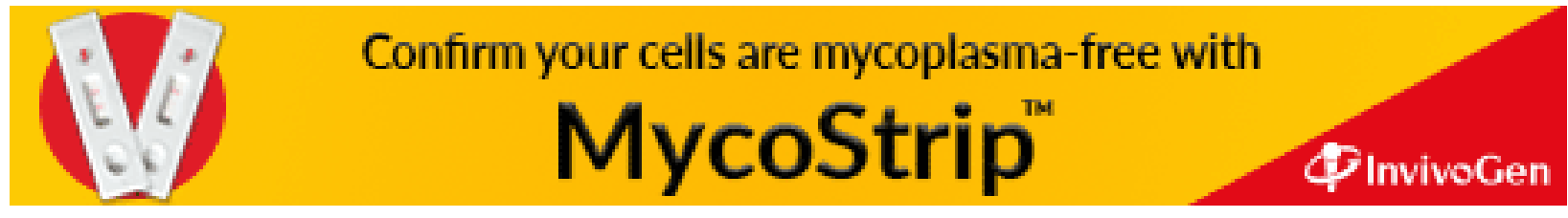

